\title{
The role of immune cells, glia and neurons in white and gray matter pathology in multiple sclerosis
}

\author{
Giulia Mallucci $^{\text {a,b, } 1}$, Luca Peruzzotti-Jametti ${ }^{\mathrm{a}, 1}$, Joshua D. Bernstock ${ }^{\mathrm{a}, \mathrm{c}}$, Stefano Pluchino ${ }^{\mathrm{a}, *}$ \\ ${ }^{a}$ Department of Clinical Neurosciences, John van Geest Centre for Brain Repair, Wellcome Trust-MRC Stem Cell Institute and NIHR Biomedical Research \\ Centre, University of Cambridge, CB2 OPY, UK \\ ${ }^{\mathrm{b}}$ Department of Brain and Behavioural Sciences, National Neurological Institute C. Mondino, University of Pavia, 27100 Pavia, Italy \\ ${ }^{\mathrm{c}}$ National Institute of Neurological Disorders and Stroke, National Institutes of Health (NINDS/NIH), Bldg10/Rm5B06, MSC 1401, 10 Center Drive, Bethesda, \\ MD 20892, USA
}

\section{A R T I C L E I N F O}

\section{Article history:}

Received 7 August 2014

Received in revised form 24 November 2014

Accepted 27 February 2015

Available online 21 March 2015

\section{Keywords:}

Neuroimmunology

Multiple sclerosis

Inflammation

Demyelination

Regeneration

Immune modulation

\begin{abstract}
A B S T R A C T
Multiple sclerosis is one of the most common causes of chronic neurological disability beginning in early to middle adult life. Multiple sclerosis is idiopathic in nature, yet increasing correlative evidence supports a strong association between one's genetic predisposition, the environment and the immune system.

Symptoms of multiple sclerosis have primarily been shown to result from a disruption in the integrity of myelinated tracts within the white matter of the central nervous system. However, recent research has also highlighted the hitherto underappreciated involvement of gray matter in multiple sclerosis disease pathophysiology, which may be especially relevant when considering the accumulation of irreversible damage and progressive disability.

This review aims at providing a comprehensive overview of the interplay between inflammation, glial/neuronal damage and regeneration throughout the course of multiple sclerosis via the analysis of both white and gray matter lesional pathology. Further, we describe the common pathological mechanisms underlying both relapsing and progressive forms of multiple sclerosis, and analyze how current (as well as future) treatments may interact and/or interfere with its pathology.

Understanding the putative mechanisms that drive disease pathogenesis will be key in helping to develop effective therapeutic strategies to prevent, mitigate, and treat the diverse morbidities associated with multiple sclerosis.
\end{abstract}

(c) 2015 Elsevier Ltd. All rights reserved.

\section{Contents}

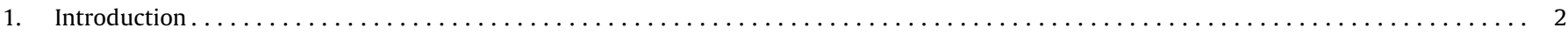

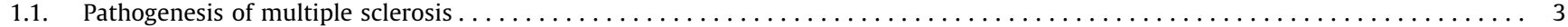

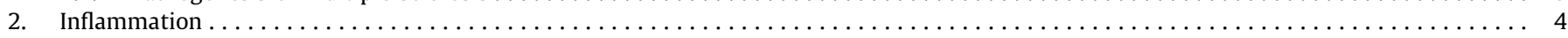

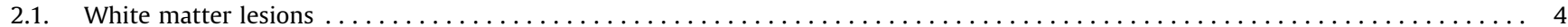

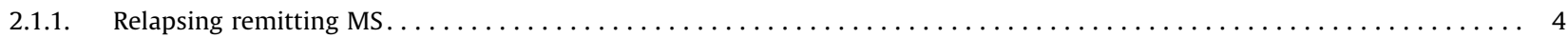

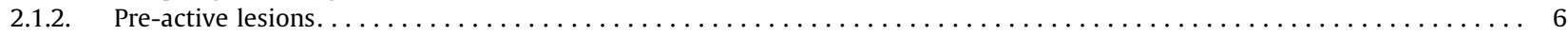

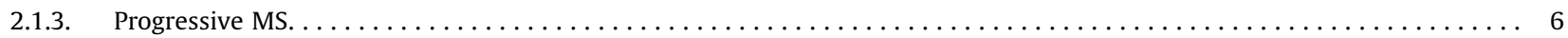

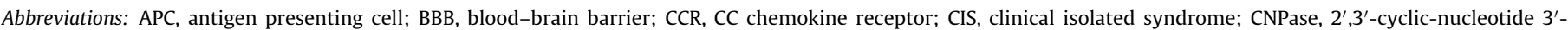

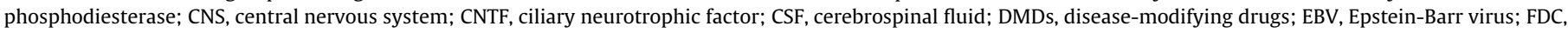

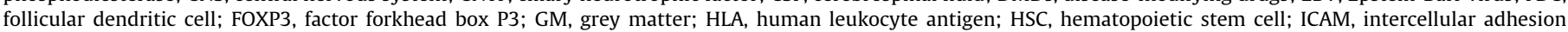

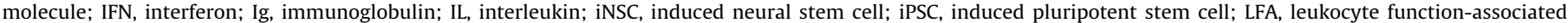

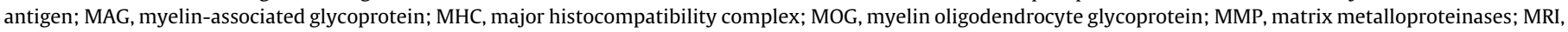

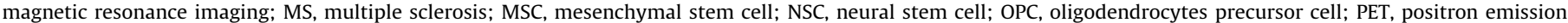

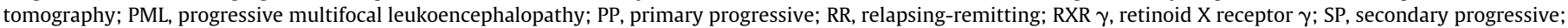

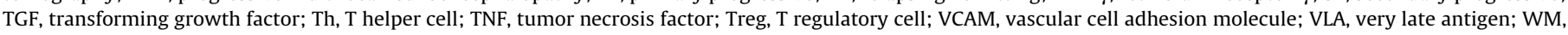
white matter.

* Corresponding author. Tel.: +44 1223331163; fax: +44 1223331174 .

E-mail address: spp24@cam.ac.uk (S. Pluchino).

1 These authors contributed equally to this work. 


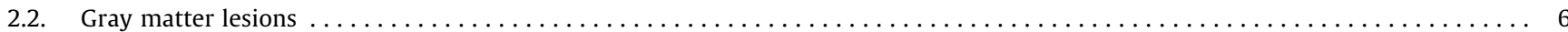

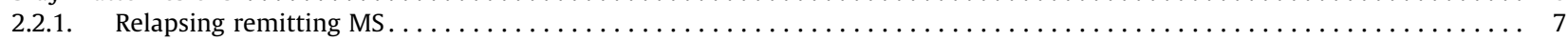

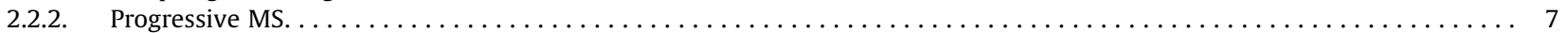

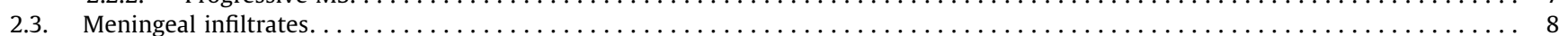

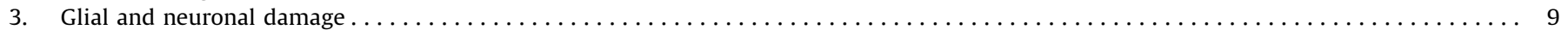

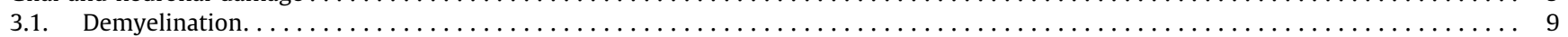

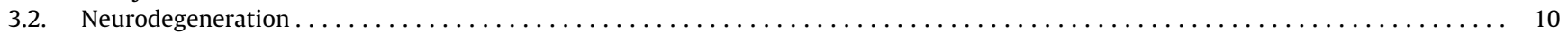

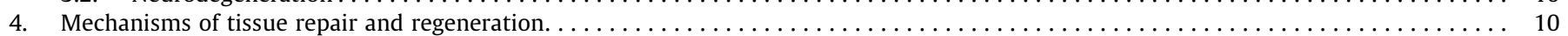

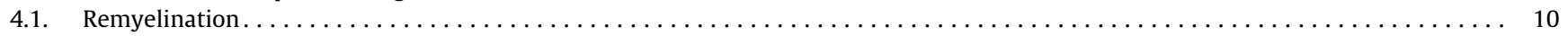

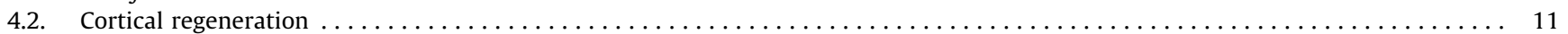

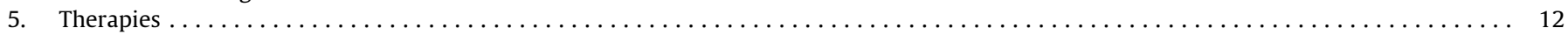

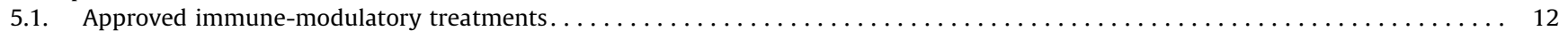

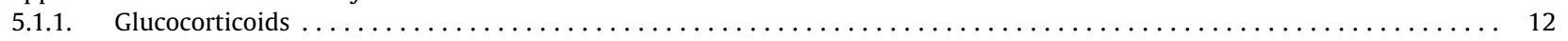

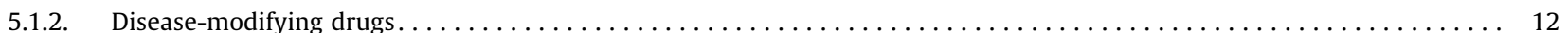

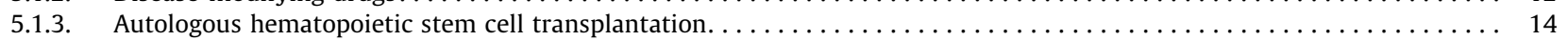

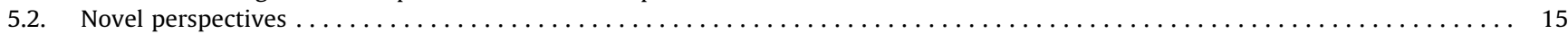

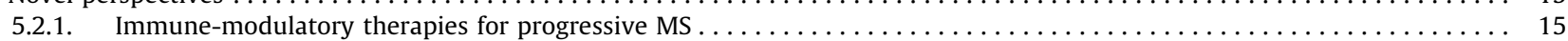

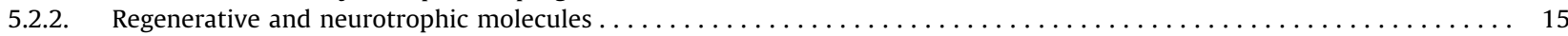

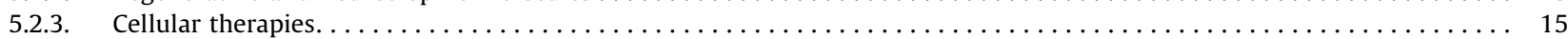

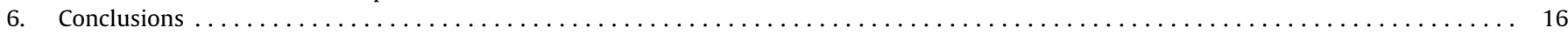

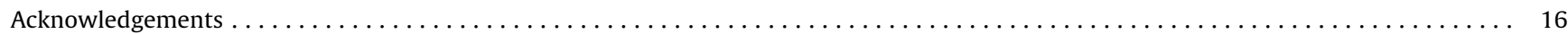

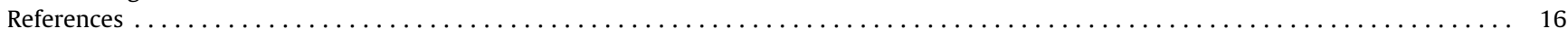

\section{Introduction}

Multiple sclerosis (MS) is an inflammatory demyelinating disease of the human central nervous system (CNS) (Compston and Coles, 2002, 2008). Recently, the International Advisory Committee on clinical trials in MS refined the two different MS phenotypes (i.e. relapsing and progressive) on the basis of both (i) disease activity and (ii) disease progression (Lublin et al., 2014) (Table 1).

Clinical isolated syndrome (CIS), which was not included in the initial clinical descriptors (Lublin and Reingold, 1996), is now recognized as the inceptive clinical presentation of a disease that displays the characteristics of an inflammatory demyelinating disorder that has yet to fulfill the criteria necessary to diagnose MS (Miller et al., 2005a,b). CIS may be either active or inactive [as defined by the clinical assessment of relapse occurrence and/or magnetic resonance imaging (MRI) activity] (Lublin et al., 2014) and typically involves the optic nerve, brainstem/cerebellum, spinal cord, or cerebral hemispheres (Polman et al., 2011). If CIS is active and fulfills current MS diagnostic criteria, the syndrome transitions to relapsing-remitting (RR) MS (Polman et al., 2011).
RR MS may also be active or inactive, and is characterized by discrete episodes of acute neurological deficits and/or worsening of a given neurological function (i.e. relapse), followed by a complete or partial recovery (i.e. remission) (Lublin and Reingold, 1996). RR MS is the most common phenotype of MS (accounting for $\sim 85 \%$ of total cases), it displays a clear association with sex (female to male prevalence is between $2: 1$ and 3:1), and develops in young adults between the ages of 20 and 30 years (Confavreux et al., 1980).

Progressive MS includes secondary progressive (SP) and primary progressive (PP) MS, both of which can be either active or inactive (as per the above) and the disease course may develop with or without progression (measured by clinical evaluation which is assessed at a minimum annually) (Lublin et al., 2014). Recent data estimate that within 5 and 15 years of an initial diagnosis of MS, 25 and $75 \%$ of patients respectively, will go on to develop SP MS (Scalfari et al., 2014). Thus the probability of disease progression increases in accordance with time after initial disease onset (Scalfari et al., 2014). Unfortunately, to date there are no clinical, imaging, immunological or pathological criteria that

Table 1

Major characteristics of MS forms as classified by (Lublin et al., 2014).

\begin{tabular}{|c|c|}
\hline Clinical form & Disease course \\
\hline Clinical isolated syndrome (CIS) & $\begin{array}{l}\text { Characterized by acute or sub acute onset of monophasic episode suggestive of MS, that has yet to fulfill the current MS } \\
\text { criteria. The episode lasts more than } 24 \mathrm{~h} \text { and usually affects the optic nerve, brain stem or spinal cord } \\
\text { Between } 30 \% \text { and } 70 \% \text { of patients with a CIS develop MS: } \\
\text { In patients with optic neuritis CIS conversion to MS varies between } 10 \% \text { and } 85 \% \\
\text { In patients with brainstem syndromes CIS conversion to MS varies between } 50 \% \text { and } 60 \% \\
\text { In patients with spinal cord CIS conversion to MS varies between } 40 \% \text { and } 60 \% \\
\text { Age of onset between } 20 \text { and } 45 \text { years } \\
\text { Female to male ratio between } 2: 1 \text { and } 5: 1\end{array}$ \\
\hline Relapsing-remitting MS (RR MS) & $\begin{array}{l}\text { Characterized by relapses over days to weeks, followed by complete or partial remissions over months or years } \\
\sim 85 \% \text { of cases } \\
\text { Age of onset between } 20 \text { and } 30 \text { years } \\
\text { Female to male ratio between } 2: 1 \text { and } 3: 1\end{array}$ \\
\hline $\begin{array}{l}\text { Progressive MS } \\
\text { Secondary Progressive MS (SP MS) } \\
\text { Primary Progressive MS (PP MS) }\end{array}$ & $\begin{array}{l}\text { Characterized by progressive accumulation of disability after initial relapsing course of the disease } \\
\sim 75 \% \text { of RR MS cases within } 15 \text { years of the initial diagnosis } \\
\text { Characterized by steady functional worsening from the onset of the disease } \\
\sim 15 \% \text { of cases } \\
\text { Later onset than RR MS ( } \sim 10 \text { years) } \\
\text { Female to male ratio: } 1: 1\end{array}$ \\
\hline
\end{tabular}


determine the conversion from RR MS to SP MS. PP MS is characterized by the progressive accumulation of disability from the onset of the disease without identifiable acute relapses, affects $\sim 15 \%$ of total MS patients, does not have a clear increase in female prevalence, and has a delayed onset as compared to RR MS (by $\sim 10$ years) (Ebers, 2004).

The reasons underlying the prodigious variability of MS clinical presentation and concordant course of disease are still under investigation, but it has been hypothesized that the different clinical patterns of MS may represent different phases of the same pathologic process (Lucchinetti et al., 2000). As such, progressive forms of MS may emerge when compensatory mechanisms of repair fail to cope with the accumulation of the axonal and neuronal damage induced by the inflammatory reaction (Franklin, 2002). Therefore, the different processes that drive demyelination at the level of white matter (WM), as well as damage of the gray matter (GM), should be interpreted as major determinants of disease heterogeneity in MS patients (Lassmann et al., 2012; Trapp and Nave, 2008). As such, a careful understanding of the role of immune cells, glia and neurons in WM and GM lesions will be pivotal in the quest to develop targeted treatments for each stage of this disorder.

Herein, we provide a broad synopsis of the role of inflammatory and CNS-specific cells during inflammation, degeneration and regeneration in the settings of both WM and GM pathology. Further, we describe the common pathological mechanisms underlying both relapsing and progressive forms of MS, and analyze how current (as well as future) treatments may interact and/or interfere with its pathology.

\subsection{Pathogenesis of multiple sclerosis}

Current data support the view of MS as a complex disease caused by a series of interactions between the environment and one's genetic susceptibility. The environment has been definitely proven to influence MS development (Ascherio and Munger, 2007a,b). For example, smokers run an increased risk of MS (Hedstrom et al., 2009). One of the most extensive case-control studies (902 cases and 1855 controls) found that the odds ratio for MS development was 1.4 for women and 1.8 for men in active smokers as compared to sex matched non-smoking controls (Hedstrom et al., 2009). Further, exposure to passive smoking was found to increase the risk of developing MS (Hedstrom et al., 2011). Interestingly, the risk of MS increases with the cumulative dose of smoking (Hedstrom et al., 2009; Hernan et al., 2001), and a threshold effect of cotinine (a nicotine metabolite) in relation to MS risk has been described (Sundstrom et al., 2008). Beyond smoking, large epidemiologic studies have demonstrated the protective effects of vitamin D with regard to the risk of developing MS (Munger et al., 2004). In line with this finding, healthy controls have higher serum levels of $25(\mathrm{OH}) \mathrm{D} 3$ and $1,25(\mathrm{OH})_{2} \mathrm{D} 3$ (the active forms of vitamin $\mathrm{D}$ ) than RR MS patients (Correale et al., 2009), and levels in patients suffering a relapse are lower than during remission (Correale et al., 2009). Of note, low serum vitamin D levels have also been associated with an increased risk of conversion to MS in patients with CIS (Ascherio et al., 2014; Martinelli et al., 2014). The molecular underpinnings of such findings may be related to induction of $\mathrm{CD} 4^{+}$factor forkhead box $\mathrm{P} 3\left(\mathrm{FOXP3}^{+}\right)$regulatory $\mathrm{T}$ cells by $1,25(\mathrm{OH})_{2} \mathrm{D} 3$ via the rendering of tolerogenic dendritic cells (Penna et al., 2005). Other relevant mechanisms may include the reported decrease in proliferation of both freshly isolated $\mathrm{CD}^{+} \mathrm{T}$ cells and myelin basic protein (MBP)-specific $\mathrm{T}$ cells by $1,25(\mathrm{OH})_{2} \mathrm{D} 3$, a reduction in the number of IL- 6 and IL-17 secreting, and/or an increase in IL-10 producing $\mathrm{T}$ cells (Correale et al., 2009).
MS affects more women than men (Confavreux et al., 1980), it is associated with other autoimmune diseases (e.g. type 1 diabetes and autoimmune thyroiditis) and has a clear genetic predisposition (Compston and Coles, 2002). Specifically, the genetic susceptibility of MS has been associated with variations of the class II Major Histocompatibility Complex (MHC) and non-MHC variants (International Multiple Sclerosis Genetics et al., 2011), which are involved in T-cell activation/regulation (Compston and Coles, 2002).

Given the complex interplay between the environment and genetics, one of the key questions in MS research that remains unanswered is whether the inflammatory reaction that occurs within the CNS is initiated by an autoimmune attack (triggered by an as of yet unidentified environmental factor in the periphery), and/or represents a response to degenerative processes that are intrinsic to the CNS (Friese and Fugger, 2007).

Two major mechanisms have come to prominence in an effort to identify the most likely triggers of MS and are as follows: molecular mimicry between self-antigens and infectious agents and bystander activation of autoreactive immune T cells (Libbey et al., 2007; Sospedra and Martin, 2005).

Molecular mimicry is a phenomenon that occurs when selfantigens and infectious agents share similar peptide sequences and/or structural motifs (Fujinami and Oldstone, 1985; Wucherpfennig and Strominger, 1995). As such, when the immune system is challenged by a relevant infection, an immune attack against epitopes shared between self and non-self is initiated. Bystander activation, as a potential mechanism leading to the onset of MS, instead requires the primary activation of tissue-resident antigen presenting cells (APCs) within the CNS (Sospedra and Martin, 2005). Once activated, these APCs allow T cells to begin an autoimmune response against CNS epitopes (Munz et al., 2009).

The most probable explanation is that these two mechanisms act jointly and in so doing together influence MS pathogenesis. The initial activation of innate immune cells within the CNS may be secondary to intrinsic (CNS specific) or extrinsic (e.g. virally mediated) damage. Such activation would subsequently lead to the leakage of CNS specific proteins from the blood-brain barrier (BBB) and their accumulation in draining lymph nodes (Stern et al., 2014). These mechanisms would in turn lead to the recruitment within the CNS of lymphocytes (from the periphery) that have been pre-primed with environmental triggers. Upon entering the CNS, lymphocytes would then induce a massive secretion of pro-inflammatory cytokines by microglia/macrophages, which would induce the destruction of CNS-tissue and the release of additional CNS antigens (i.e. epitope spreading) (McMahon et al., 2005; Owens et al., 2011; Sospedra and Martin, 2005).

While the precise targets of this autoimmune response have yet to be fully elucidated, a series of relevant self-antigens have been identified over the past years, such as myelin oligodendrocyte glycoprotein (MOG), proteolipid protein (PLP), myelin associated glycoprotein (MAG), myelin basic protein (MBP), 2',3'-cyclicnucleotide $3^{\prime}$-phosphodiesterase (CNPase), $\alpha \mathrm{B}$ crystalline, and S100 $\beta$ protein (McCarthy et al., 2012; Sospedra and Martin, 2005). Concordantly, the most widely excepted experimental animal model of MS (experimental autoimmune encephalomyelitis or EAE) is induced using myelin antigens such as MBP, PLP, MAG, and MOG (Petry et al., 2000; Steinman, 1995). One of the bestcharacterized self-antigens, MBP (the major constituent of myelin in the CNS), shares both MHC class II and T cell receptor-binding motifs with several viruses [e.g. herpes viruses and Epstein-Barr (EBV)]. In particular, EBV, which has been detected in both MS lesions (Peferoen et al., 2010; Sargsyan et al., 2010; Serafini et al., 2007; Willis et al., 2009) and in serum-epidemiological studies, 
may represent one of the major factors triggering MS (Ascherio and Munger, 2007a). It is known that primary EBV infection (EBV seroconversion) increases the risk of developing MS (Levin et al., 2010) and this risk is higher with an increasing titer of antibodies against the EBV nuclear antigen (Munger et al., 2011). Further, Serafini et al. have found meningeal B cells within lymphoid follicular structures in SP MS patients to be positive for EBV small nuclear mRNA and immunoreactive for the EBV nuclear antigen, latency membrane protein-1, and the BFRF1 lytic protein (Serafini et al., 2007). However, this data remains controversial, as subsequent work has failed to detect EBV within the meninges in the vast majority of MS patients (Willis et al., 2009).

The abovementioned, together with the putative role of endogenous retroviruses in MS pathogenesis (Nissen et al., 2013), does suggest that viruses might play a prominent role in inducing the initial activation of innate immune cells (Lang et al., 2002; Wucherpfennig and Strominger, 1995).

\section{Inflammation}

\subsection{White matter lesions}

WM lesions in MS were first described by Charcot over 165 years ago in the course of post-mortem studies, as multiple focal sclerotic plaques scattered throughout the WM of the brain and the spinal cord (Charcot, 1848). Both early neuropathological reports and contemporary MRI findings have clearly demonstrated that WM lesions have a tendency to involve the optic nerve and a propensity to locate to the periventricular WM, juxtacortical border and to the cerebellum/brainstem of MS patients (Charcot, 1848; Fazekas et al., 1999). WM brain lesions are commonly round or ovoid in nature and range from a few millimeters to more than one centimeter in size. WM abnormalities are also found in the spinal cord of $\sim 90 \%$ of MS patients (Nijeholt et al., 1998). These spinal cord lesions are typical located in the cervical region and are aligned with the long axis of the cord. Further, they usually extend less than two vertebral segments in length and typically involve less than half of the axial cord (Lycklama et al., 2003).

MRI is currently the most sensitive technique for detecting WM lesions in vivo (Montalban et al., 2010) and its role in the diagnosis of clinical MS is paramount (Barkhof et al., 1997; Polman et al., 2011). Nonetheless, the pathological examination of MS lesions can still provide valuable insights into the progression of the different types and/or stages of the disease process. The initial pathological classification of WM lesional activity was based on the presence of MHC class II receptors, adhesion molecules, cytokines, and the activation state of infiltrating lymphocytes and macrophages (Adams et al., 1989). However, this classification system was inadequate, as it could not discriminate between inflammatory and demyelinating activity within the lesions. To overcome this limitation, a new categorization of active WM lesions was put forth to combine the state of macrophage activation and concomitant myelin degradation (Bruck et al., 1996). Active MS demyelinating lesions are now segregated into four distinct patterns that arise from distinct pathophysiological mechanisms (please refer to the demyelination section for further details on the pathogenesis of the different lesional patterns in MS) (Lucchinetti et al., 2000).

Pattern I lesions (Fig. 1A) are found in $~ 10 \%$ of total MS patients, with a higher incidence in those suffering from acute MS (i.e. $<1$ year of disease history), and are characterized by sharply demarcated lesional edges with perivascular infiltrating $T$ cells and active demyelination with activated microglia and myelin-laden macrophages (Lucchinetti et al., 2000). Pattern II lesions (Fig. 1B) are found in $\sim 55 \%$ of total MS patients and are characterized by a massive infiltration of $\mathrm{T}$ cells and myelin-laden macrophages with prominent deposition of immunoglobulins (Ig)s, mainly IgG, and complement (i.e. C9neo) antigen at sites of active myelin destruction (Lucchinetti et al., 2000). Pattern III lesions (Fig. 1C) are found in $\sim 30 \%$ of total MS patients, and are characterized by illdefined borders, with dying oligodendrocytes and inflamed vessels surrounded by a rim of spared myelin with an early preferential loss of MAG and CNPase immunoreactivity (Lucchinetti et al., 2000). Pattern IV lesions are quite rare (Fig. 1D), they are found only in PP MS patients ( $\sim 5 \%$ of the cases), and show infiltrating $\mathrm{T}$ cells and activated microglia/macrophages with extensive nonapoptotic oligodendrocyte degeneration in the peri-lesional WM adjacent to the active lesion (Lucchinetti et al., 2000).

It has recently emerged that patients presenting with one lesional pattern tend to conserve that pattern throughout the course of their disease (i.e. intra-individual homogeneity) (Metz et al., 2014). This concept has been challenged by other authors, who have described an intra-individual temporal heterogeneity of lesions (i.e. a progression from heterogeneity to homogeneity of lesional subtype over the course of the disease) (Breij et al., 2008). Despite such controversy, it is clear that during the disease course, the four active lesional patterns become fully demyelinated and ultimately convert to a common inactive morphology. Understanding how these different inflammatory lesional patterns evolve during early vs. chronic phases of the disease will shed light on the mechanisms that drive MS activity and progression.

\subsubsection{Relapsing remitting $M S$}

Orchestrated lymphocytic activation is the major driver of WM damage and guides the evolution of WM lesions. The initial phase of the inflammatory response in MS is characterized by peripheral activation of $\mathrm{T}$ cells with encephalitogenic potential (i.e. T cells that recognize specific molecules of the CNS) (Wekerle et al., 1987). Activated $\mathrm{T}$ cells up-regulate the expression of $\alpha 4$-integrins on their surface, which mediate a transient binding with vascular cell adhesion molecules (VCAMs) expressed on endothelial cells (Engelhardt and Ransohoff, 2012). Particularly CD49, the $\alpha 4$ subunit of very late antigen (VLA)-4 receptor, is involved in the migration of immune cells across the BBB by interacting with endothelial VCAM-1. After this initial interaction, activation of G-coupled protein signaling leads to an increase in the affinity of $\alpha 4$ and $\beta 2$ integrins for VCAMs, thereby allowing the full arrest of T cells on the vascular wall. Integrin-mediated adhesion and polarization eventually promotes $\mathrm{T}$ cell crawling on the endothelium, which is predominantly regulated by high affinity leukocyte function-associated antigen (LFA)-1 and its endothelial ligands, intercellular adhesion molecules (ICAMs)-1/2. T cells then cross the endothelial layer via diapedesis (Engelhardt and Ransohoff, 2012), the endothelial basement membrane via $\alpha 6 \beta 1$ integrindependent activation (Sixt et al., 2001; Wu et al., 2009), and the glia limitants via the secretion of matrix metalloproteinases (MMP) (i.e. MMP-2 and MMP-9) (Agrawal et al., 2006; Toft-Hansen et al., 2004). Upon CNS entry, encephalitogenic T cells start to release pro-inflammatory cytokines, [e.g. interferon (IFN)- $\gamma$ or osteopontin], which activate microglia (Chabas et al., 2001).

Activated microglia/macrophages in turn secrete chemokines of the CXC family [interleukin (IL)-8, CXC-ligand-10)] and of the CC family (macrophages inflammatory protein-1a/1b, monocyte chemoattractant protein-1, CC-ligand-5), which contribute to the intracerebral recruitment of $\mathrm{T}$ cells, additional macrophages, and dendritic cells (Aloisi, 2001). Local and infiltrating activated APCs present myelin antigens associated with MHC class II and express co-stimulatory molecules (e.g. CD40 and B7 glycoproteins) capable of further activating infiltrating lymphocytes (Sanders and De Keyser, 2007). Pro-inflammatory cytokines [e.g. tumor necrosis factor (TNF)- $\alpha$ and IFN- $\gamma$ ], reactive oxygen species, and proteolytic/lipolytic enzymes are also released by activated 

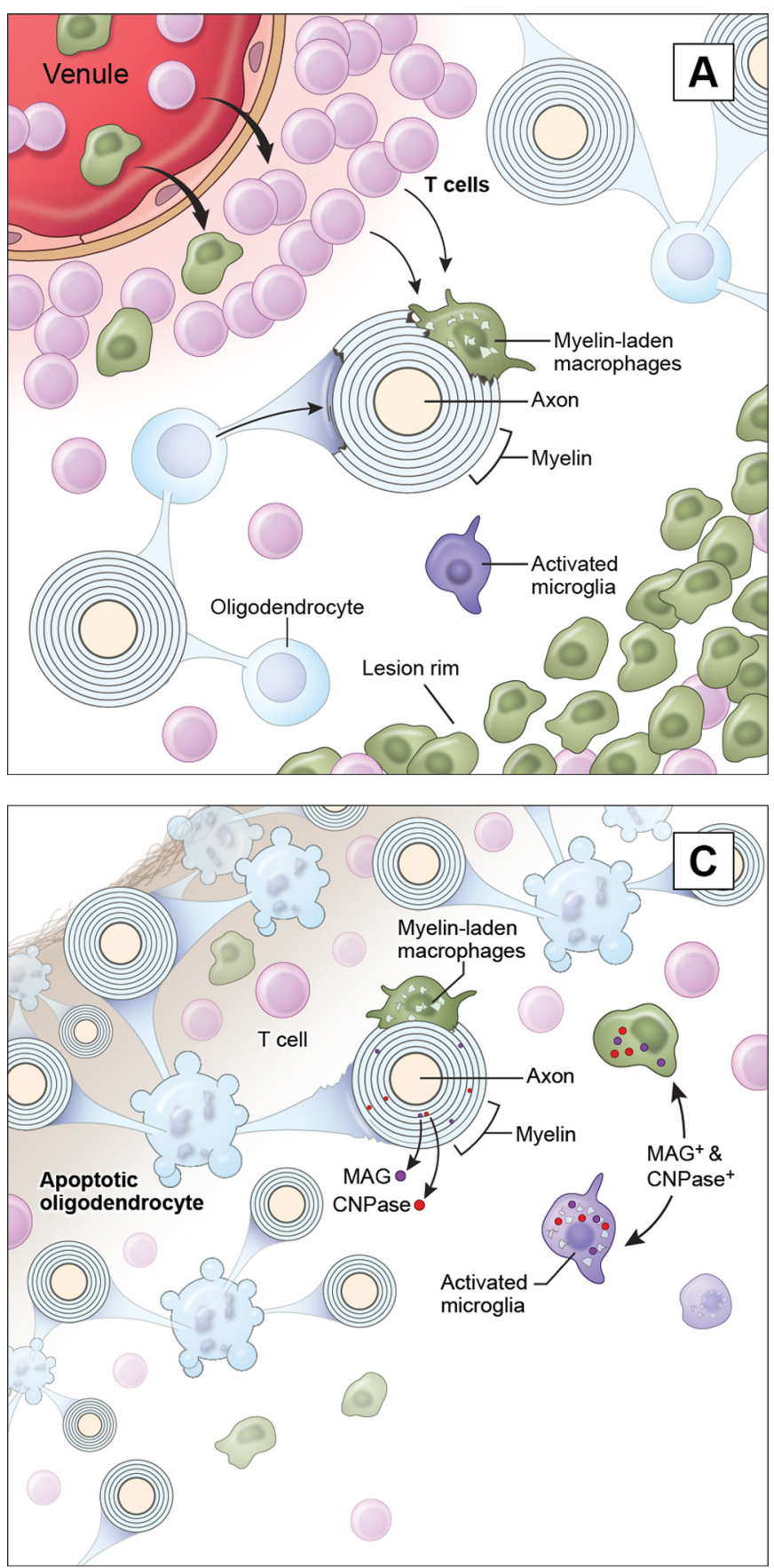
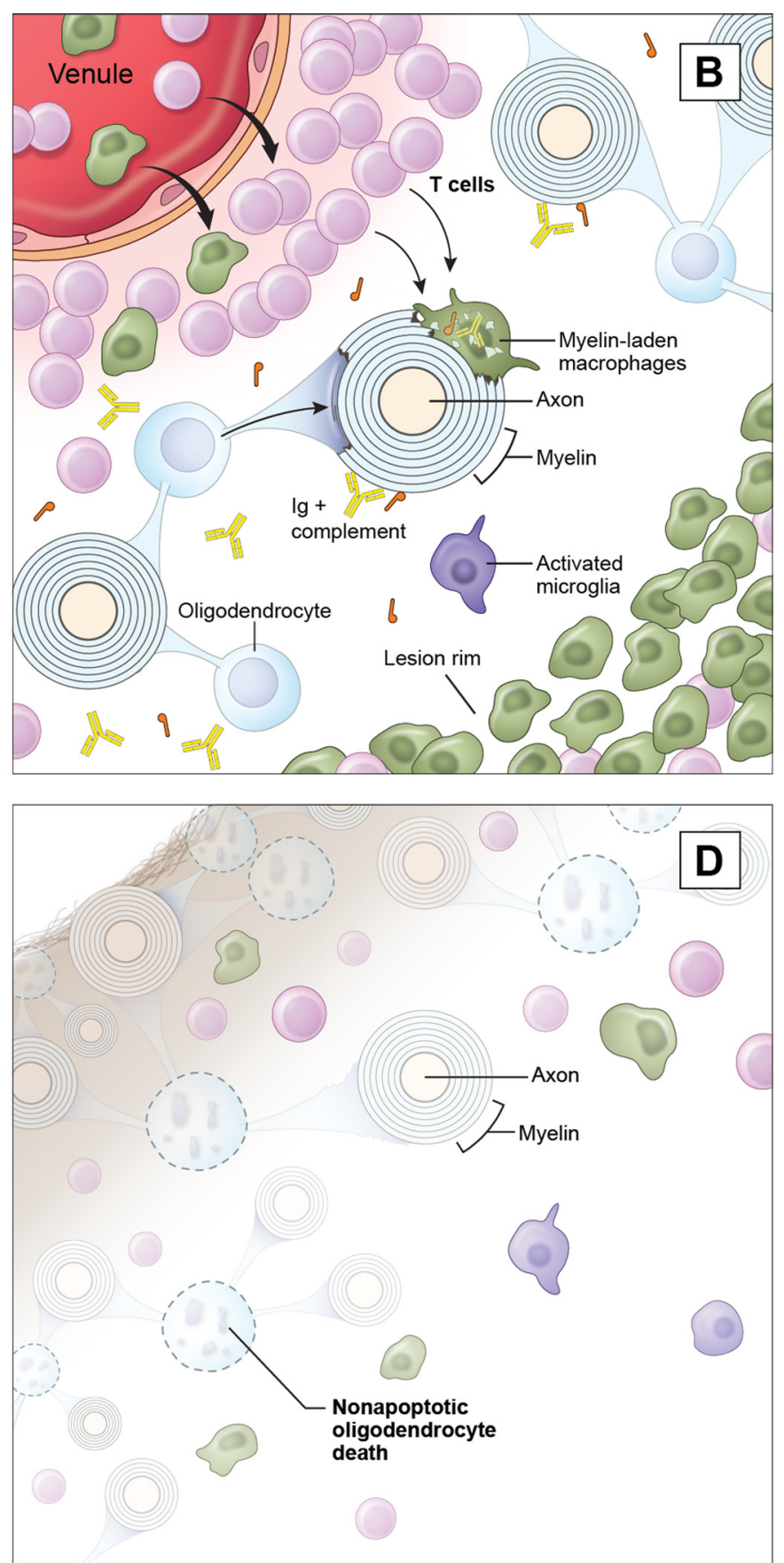

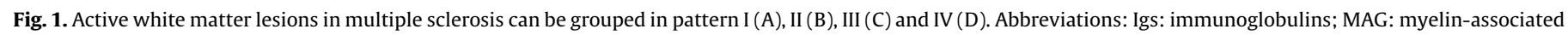
glycoprotein; CNPase: 2',3'-Cyclic-nucleotide 3'-phosphodiesterase.

microglia/macrophages, and further amplify the initial activation of T cells (McMahon et al., 2005; Greter et al., 2005; Heppner et al., 2005).

Different subtypes of T cells (e.g. $\mathrm{CD} 8^{+}$and $\mathrm{CD} 4^{+}$) participate in the autoimmune response and in so doing play vastly different roles with regard to the final pathological outcome. $\mathrm{CD}^{+}$cytotoxic $\mathrm{T}$ lymphocytes are known to be major constituents of inflamed plaques and play a key role in axonal transection and oligodendrocyte death (Johnson et al., 2007). Moreover, data from preclinical studies show that $\mathrm{CD}^{+}$cytotoxic $\mathrm{T}$ cells may increase the vascular permeability of the BBB via a perforin-dependent mechanism (Johnson et al., 2005).

The role of $\mathrm{CD}^{+} \mathrm{T}$ cells notwithstanding, MS has traditionally been viewed as a $\mathrm{CD} 4^{+} \mathrm{T}$ cell-mediated autoimmune disease. Among effector $\mathrm{CD}^{+} \mathrm{T}$ cells, $\mathrm{T}$ helper (Th) cells have divergent roles upon their differentiation into either a pro-inflammatory (Th1) or antiinflammatory (Th2) phenotype. Th1 polarization is promoted by IL- 12 and characterized by the secretion of IFN- $\gamma$, TNF- $\alpha$, TNF- $\beta$, and IL-2 (Abbas et al., 1996; Murphy and Reiner, 2002). The Th2 phenotype is instead promoted by IL- 4 and characterized by the secretion of anti-inflammatory cytokines, which include IL-3, IL-4, IL-5, IL-6, IL-10 and IL-13 and transforming growth factor (TGF)- $\beta$ (Abbas et al., 1996; Murphy and Reiner, 2002). The identification of a distinct $\mathrm{CD} 4^{+}$cell subpopulation that produces IL-17 (designated as Th17 cells) led to a revision of the abovementioned paradigm (i.e. Th1/Th2 axis) in MS (Sung et al., 2008). The Th17 cell phenotype is dependent on several factors (IL-1, IL-6, IL-21, IL-23, TGF- $\beta$ ), among which IL-23 is essential in driving Th17 lymphocyte expansion. 
Th17 cells are further characterized by the production of IL-17A, IL-17F, IL-22 (which are major determinants of BBB derangement in MS) as well as IL-21, IL-9 and TNF- $\alpha$ (Sung et al., 2008).

The equilibrium between Th cells and other $\mathrm{T}$ cell subsets [particularly natural and adaptive $T$ regulatory (Treg) cells)] within the sites of inflammation is critical in determining the evolution of CNS pathology (Sakaguchi et al., 2006). Natural Treg cells express CD25 and the transcription of FOXP3, and are essential for controlling autoimmunity by mediating immunological tolerance to self-antigens (Sakaguchi et al., 2006). Adaptive Treg cells, including Treg- 1 , Th3 and various subsets of $\mathrm{CD}^{+}$Treg cells, instead exert their immune suppressive functions primarily via IL-10 (Treg-1) and TGF- $\beta$ (Th3) secretion. Clearly, both natural and adaptive Treg cells play a fundamental role in maintaining immune homeostasis, and profoundly shape autoimmune inflammation during MS (Sakaguchi et al., 2006). In line with this, clinical evidence supports the contention that much of the initial underlying disease pathogenesis may be attributed to the reduced functional capacity of circulating regulatory T-cells. Coordinate with this, Viglietta et al. reported a significant decrease in the effector function of $\mathrm{CD}^{+} \mathrm{CD} 25^{\text {high }}$ regulatory $\mathrm{T}$ cells from the peripheral blood of patients with MS as compared to healthy controls. Differences were also apparent in single cell cloning experiments in which the cloning frequency of $\mathrm{CD} 4^{+} \mathrm{CD} 25^{\text {high }}$ $\mathrm{T}$ cells was significantly reduced in patients as compared with normal controls (Viglietta et al., 2004).

Several lines of evidence support a role for B cells and antibodies in MS pathogenesis (Hauser et al., 2008), challenging the concept that MS is a disease driven solely by activated T cells (Owens et al., 2006) (please refer to the demyelination section for further details). Increased levels of Igs in the cerebrospinal fluid (CSF) of MS patients, which appear as oligoclonal bands after immunoelectrophoresis, indeed represent one of the hallmarks of MS (Link and Huang, 2006). B cells exert multiple pro-inflammatory and regulatory functions in MS pathology: (i) they differentiate into plasma cells and secrete Igs which can process antigen for $\mathrm{T}$ cell activation and/or for macrophage phagocytosis; (ii) they act as APCs for auto-reactive T cells; and (iii) they secrete both pro-inflammatory (e.g. IL-6, IL-12, TNF), and anti-inflammatory (e.g. IL-10) cytokines (Krumbholz et al., 2012).

\subsubsection{Pre-active lesions}

The observation of clusters of activated microglia (HLA-DR ${ }^{+}$, $\mathrm{CD}^{+} 8^{+}$and $\mathrm{CD} 45^{\text {high }}$ ) within the CNS of MS patients in the absence of BBB derangement, demyelination, axonal loss, and $\mathrm{T}$ cell activation, has challenged previous theories on MS pathogenesis (Van der Valk and Amor, 2009). These pre-active lesions are not associated with a specific MS sub-type [being that they are typically found in similar number and size in RR, as well as in SP and PP MS patients (De Groot et al., 2001)], and can be identified as part of the normal appearing WM (Filippi et al., 2012).

The lack of BBB breakdown described in pre-active lesions lends support to the hypothesis that MS may in part be driven by an innate immune response within the CNS itself, independent of direct/causative peripheral immune factors (van Noort et al., 2011). As such, microglia activation may be considered the initiator of pathologic alterations within the CNS. The BBB would then be secondarily affected by factors released by activated microglia (e.g. IL-17, TNF- $\alpha$ ) and/or directly by factors that trigger the initial microglial response (van Noort et al., 2011). However, it is prudent to note that these lesions are not necessarily synonymous with early disease activity, but may rather be a consequence of a diffuse, persistent activation of innate immune cells.

The ultimate fate of pre-active lesions seems to be regulated by both neurodegenerative and neuroprotective factors released by activated microglia/macrophages. On one side, microglia/ macrophage activation is associated with the release of proinflammatory cytokines (e.g. TNF- $\alpha$ and IFN- $\gamma$ ), reactive oxygen species, proteinases and various complement proteins (Mayo et al., 2012). On the other side, microglia/macrophages may play a beneficial, anti-inflammatory role by secreting nerve growth factor, brain-derived neurotrophic factor, insulin-like growth factor-1, as well as an variety of anti-inflammatory cytokines (e.g. IL-10 and TGF- $\beta$ ) (Mayo et al., 2012). It is known that the function of macrophages may be related to their capacity to assume distinct activation states, which are roughly divided into a pro-inflammatory (classically-activated) M1-like state (associated with host defense, cytotoxicity, secretion of pro-inflammatory cytokines, proteases and reactive oxygen and nitrogen species) and an anti-inflammatory (alternatively-activated) M2-like state (associated with an increase in angiogenic capacity, and the secretion of anti-inflammatory cytokines, growth and neurotrophic factors) (Biswas and Mantovani, 2010; Miron and Franklin, 2014). It is interesting to note that M2-polarized macrophages exist within pre-active lesions where they help to maintain a state in which tissue damage remains reversible, thus representing a novel and attractive future therapeutic target (Van der Valk and Amor, 2009; van Noort et al., 2011).

\subsubsection{Progressive MS}

As previously stated, the different inflammatory MS lesional patterns ultimately converge into a morphologically demarcated hypo-cellular area that contains only a minimal amount of macrophages characterized by periodic acid Schiff degradation products and/or empty vacuoles (Lucchinetti et al., 1999). Due to a longer course of disease, these inactive lesions have a higher prevalence in progressive MS, compared to RR MS patients (Prineas et al., 2001). Interestingly, within progressive MS subtypes, inactive lesions display different characteristics, with an increased number of incompletely remyelinated axons found in SP MS compared to PP MS patients (Bramow et al., 2010). This difference may suggest that the mechanisms affecting CNS repair in SP MS are different from those that occur in PP MS and may depend on the presence of an intrinsic block in remyelination (please refer to the remyelination section for further details), and/or the persistence of an (inhibitory) inflammatory milieu (Patrikios et al., 2006).

In support of this latter hypothesis, a slowly expanding demyelination (from the lesional core) is a typical finding of many inactive lesions in SP MS. These slowly expanding lesions are characterized by a hypo-cellular center (morphologically defined by a complete loss of microglia/macrophages and oligodendrocytes), a dense astrocytic scar, and an external border of activated microglia (Lassmann, 2011). Slowly expanding lesions are probably due to the evolution of pre-existing active lesions, in which minor demyelinating activity is still present despite the absence of major BBB damage (Frischer et al., 2009; Prineas et al., 2001). However, the profound loss of microglia/macrophages within the center of these lesions, suggests that the mechanism of demyelination may be somewhat different from that of active lesions. As such, the modest perivascular cuffing and the impaired phagocytosis of myelin (i.e. myelin fragments found on the surface of microglia/macrophages) point towards an inefficient clearance of myelin debris, which is in part responsible for the failure of remyelination and perpetuation of the local inflammatory response (Prineas et al., 2001).

\subsection{Gray matter lesions}

Involvement of the GM in MS was initially described in the late 1800 s by Charcot, who was the first to point out the existence of demyelinated lesions within the GM of brain convolutions (JM, 1877). However, due to the inherent difficulties in the visualization of GM lesions using traditional histological methods, his findings 
were initially neglected. The first extensive analysis of GM lesions within a cohort of MS autopsies was performed by Brownell and Hughes in 1962 (Brownell and Hughes, 1962). These authors found that $\sim 26 \%$ of the total number of MS lesions were actually located in the cortical GM and/or at the border with the WM. The extent of GM involvement in MS has since been confirmed using myelin specific protein immunohistochemistry, and today the critical importance of GM pathology in MS is well accepted (Bo et al., 2003a; Peterson et al., 2001). Advanced imaging techniques have firmly established that cortical demyelination is in fact a common feature of MS, independent from the clinical course of the disease, and may even be equal and/or in excess of WM lesional load (Filippi and Rocca, 2012; Geurts, 2012). Clearly, the study of the pathophysiology of GM involvement in MS is of pivotal importance if one seeks to understand the origins of disease, response to treatment and/or accurately predict patient prognosis.

Early descriptions of cortical lesions in MS were obtained from patients with progressive MS. This selection bias led the scientific community to believe that GM lesions differed significantly from those involving the WM, which had been primarily characterized by substantial infiltration of peripheral leukocytes and BBB derangement (Bo et al., 2003a). As compared to WM lesions, cortical lesions were then assumed to be less inflammatory and contain fewer microglia/macrophages (Peterson et al., 2001) and $\mathrm{T}$ cells (Bo et al., 2003a). Given this putative absence of overt inflammation within GM lesions, the pathological classifications of cortical lesions in MS are still based on their position within the parenchyma, rather than the pertinent characteristics of the inflammatory infiltrate.

The first classification of GM lesions, identified seven types which depended on their relationship to the cortical veins (Kidd et al., 1999). Due to its complexity, this initial classification system was replaced by a simpler categorization of GM lesions, which currently identifies four main types according to their location within the cortical GM (Calabrese et al., 2009; Peterson et al., 2001). Type I lesions, also called leukocortical lesions, are areas of demyelination that project radially from small vessels, and involve both the deeper layers of the GM and the contiguous GM/WM junction. These lesions are the second most prevalent in progressive MS (representing 38\% of total lesions) and are characterized by a substantial cell (both glial and neuronal)/synaptic loss (Wegner et al., 2006). Type II lesions, also called intracortical lesions, are small, perivascular areas of demyelination that are confined within the cortex and spare both the superficial cortex as well as the underlying WM. These lesions are relatively less frequent in progressive MS (representing $18 \%$ of total lesions) than other lesion types (Wegner et al., 2006). Type III lesions extend from the pial surface into the first cortical layers (with the majority reaching layers 3 or 4 ) and can transverse multiple/adjacent gyri. Finally, type IV lesions extend from the pial surface and encompass the entire width of the cortex, yet do not involve the subcortical WM. Given their similarity, type III and IV lesions are called subpial lesions and contribute significantly to the total lesion load in MS (44\% of GM lesions) (Wegner et al., 2006). Subpial lesions can also be quite extensive, affect more than $60 \%$ of the cortical ribbon within the brain (Kutzelnigg et al., 2005), and extend to deep neuronal structures (Geurts et al., 2007).

Despite the validity of the described classification system for patients with chronic MS, recent research on brain biopsies obtained from patients with early MS have revealed that GM lesions do in fact show profound lymphocytic infiltration, increased BBB damage and meningeal inflammation at their very onset (Lucchinetti et al., 2011).

\subsubsection{Relapsing remitting $M S$}

Cortical demyelination and BBB damage occur early in the disease course of MS and often precede the appearance of classic
WM plaques (Calabrese and Gallo, 2009; Popescu et al., 2011) [it has been noted that $37 \%$ of patients with a CIS show the presence of GM pathology (Calabrese et al., 2007)]. Cortical lesions are more numerous - and cortical atrophy is more pronounced - in certain subgroups of RR MS patients (Popescu and Lucchinetti, 2012). For example, RR MS patients with cognitive deficits have more GM lesions than RR MS patients without cognitive impairment (Calabrese et al., 2009). Similarly, a more severe - and rapidly evolving - cortical lesion load is found in RR MS patients with epilepsy (Calabrese et al., 2012a).

Throughout the disease course, GM lesions represent an important aspect of MS pathology. A longitudinal MRI study of 64 MS cases (38 of whom were classified as RR MS) documented periodic peaks of increased diffusion coefficients in the normal appearing cortex, perhaps reflecting episodes of focal and diffuse cortical damage caused by local inflammatory reactions (Vrenken et al., 2006). The majorities of cortical lesions in early MS are highly inflammatory in nature and show an accumulation of myelinladen macrophages, $\mathrm{T}$ cell and B cell perivenular infiltrates, as described for active WM lesions (Lucchinetti et al., 2011). In representative tissues from early MS cases, $82 \%$ of lesions showed extensive $\mathrm{T}$ cell infiltrates, while $41 \%$ showed macrophageassociated demyelination (Lucchinetti et al., 2000, 2011). Interestingly, lymphocytes, microglia/macrophages were predominantly seen in apposition to pyknotic neurons and neurites, thus suggesting a direct role in the final stages neuronal damage/death (Popescu and Lucchinetti, 2012).

\subsubsection{Progressive MS}

Several authors have pointed out that cortical demyelination is one of the main pathologic drivers of disease progression in MS. A five year longitudinal study on more than 300 MS patients has shown that GM and WM changes occur partly independently, and that GM damage is strongly associated with both physical and cognitive disability progression, more so than WM lesion load (Calabrese et al., 2012b). As such, GM lesions may provide a pathological correlate for the cognitive and executive dysfunction that commonly arises in the vast majority of MS patients during disease progression (Chiaravalloti and DeLuca, 2008).

Cortical demyelination in patients with progressive MS has mainly been detected in the cingulate gyrus, and the frontal, temporal and insular cortices (Popescu and Lucchinetti, 2012). Another brain area that displays extensive cortical demyelination is the cerebellum, where $39 \%$ of the cortex was found to be demyelinated in SP MS patients and 37\% in PP MS patients (Kutzelnigg et al., 2007). Among the deeper brain structures, the hippocampus exhibits prominent demyelination (in 78\% of chronic MS) (Geurts et al., 2007) and deficits in memory and visuospatial learning correlate with regional hippocampal atrophy (Longoni et al., 2013). Demyelination has been also reported in other GM areas including the basal ganglia (e.g. thalamus) and the spinal GM (Geurts et al., 2009).

Activated microglial cells represent the vast majority of phagocytic cells in cortical lesions of patients with chronic progressive MS, and are found in close association with degenerating neurites and neuronal cell bodies (Peterson et al., 2001). Among the different types of GM lesions, type II lesions are characterized by the lack of lymphocytic and macrophagic inflammatory infiltrates, complement deposition and BBB breakdown. Conversely, type I lesions are more inflammatory, but still less than classically activated WM lesions (Bo et al., 2003a,b; Calabrese et al., 2013; Popescu and Lucchinetti, 2012). GM damage appears to play a pivotal role in determining the clinical course of MS, and the combined assessment of both WM and GM involvement may prove useful in predicting disease progression/ treatment responses moving forward. 


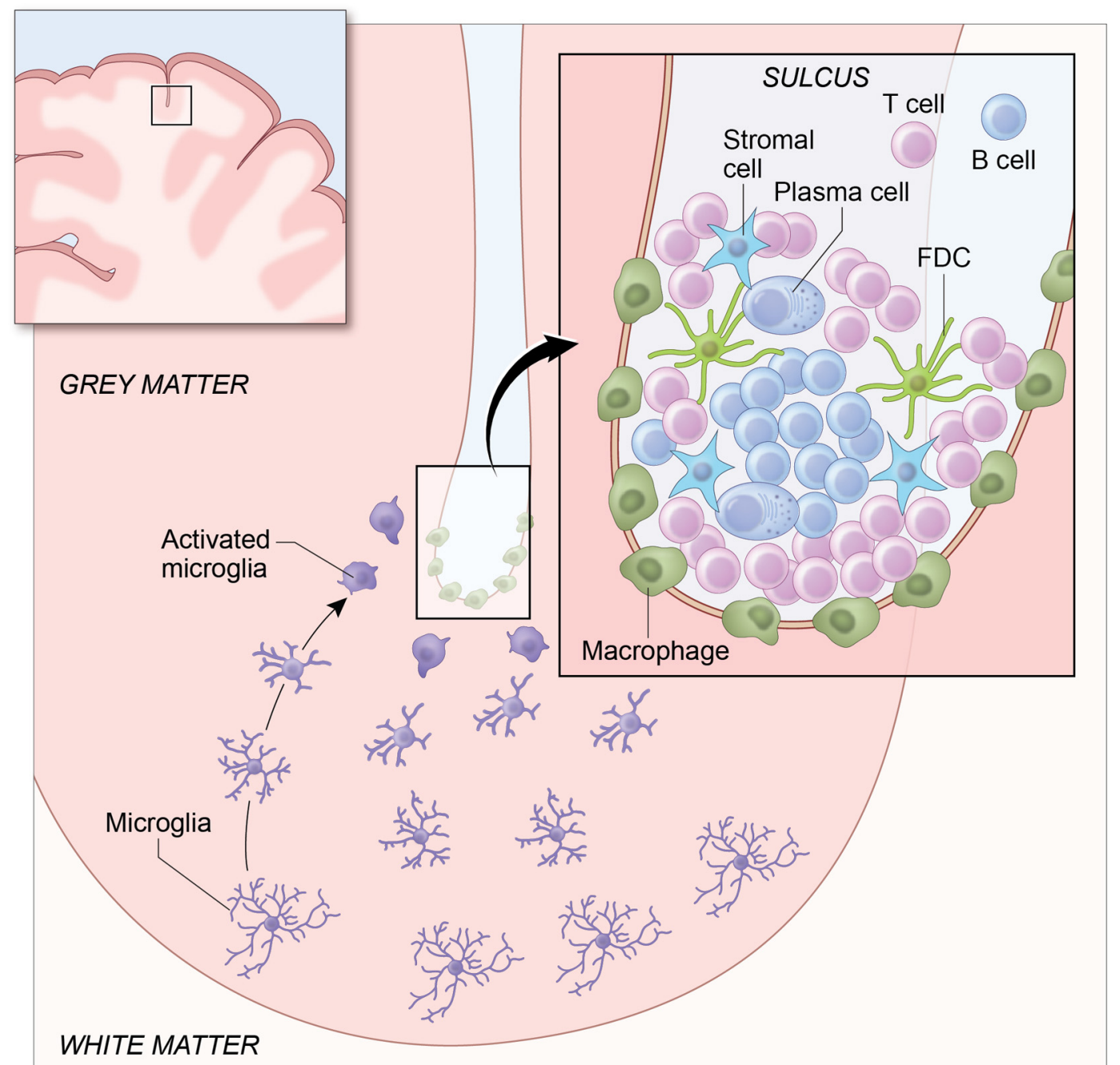

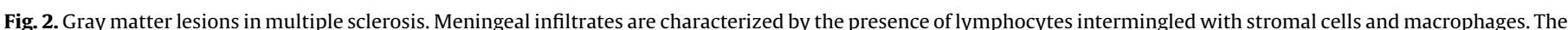

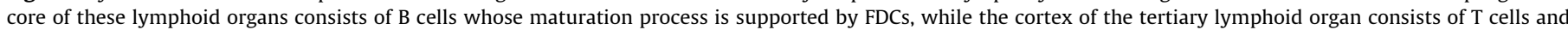

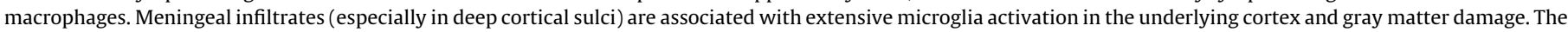

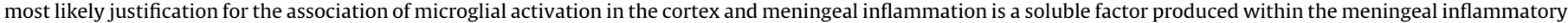
infiltrate and accumulated in the cerebrospinal fluid. Abbreviations: FDCs: follicular dendritic cells.

\subsection{Meningeal infiltrates}

A salient feature of cortical demyelination in early and late MS is its topographic link to meningeal inflammation (Fig. 2). In early MS a moderate-to-severe meningeal inflammation is associated with cortical demyelination in a statistically significant manner ( $\sim 90 \%$ probability), especially for subpial plaques, when compared with type I and II lesions (Lucchinetti et al., 2011). Interestingly, both diffuse meningeal inflammation and focal perivascular meningeal infiltration of $\mathrm{T}$ cells and $\mathrm{B}$ cells were shown to be significantly associated with cortical lesions in early MS. In late-stage progressive MS meningeal inflammatory infiltrates have been extensively identified and topographically related to the subpial demyelination of the underlying cortex (Kutzelnigg et al., 2005).

Although GM lesions display a remarkable difference between the early and late phases of MS, the shared hallmark of meningeal inflammation does suggest a common underlying pathological process. Major insights into this phenomenon came from the pathological analysis of progressive MS patients, which showed a prevailing population of microglial cells within areas of cortical demyelination close to meningeal inflammatory infiltrates, thus suggesting the existence of an inflammatory process within the GM that is driven by the meningeal infiltrates (Howell et al., 2011).
In line with the aforesaid, consistent in vivo imaging of microglia activation by PK11195 positron emission tomography (PET) binding has revealed extensive regional activation of microglia in the MS cortex of both RR MS (40\% of cases) and SP MS patients (75\% of cases) (Politis et al., 2012).

The putative mechanisms governing the interactions between inflammatory cells accumulating in the GM and in the meningeal infiltrates have yet to be fully elucidated. However, the most likely justification for the association of GM damage and meningeal inflammation is that soluble factors produced within the meningeal inflammatory infiltrates diffuse into the adjacent cortex, and induce cortical damage directly and/or through microglia activation (Choi et al., 2012). Interestingly, subpial demyelination preferentially involves the deep cortical sulci, thus suggesting that it may be induced by stagnant mediators that are transported by the physiological flow of the CSF (Popescu and Lucchinetti, 2012). There is uncertainty with regard to which cell type may be the source of these reputed mediators. The observation that B cells, plasma cells and myelin-specific antibodies are present in MS lesions - and that Igs levels are increased in the CSF of MS patients - does provide supporting evidence for a role of B cells/humoral immunity in MS pathogenesis (Presslauer et al., 2008). It is tempting to speculate that a B cell 
derived mediator would be the key player in the pathogenesis of GM damage in MS (Torkildsen et al., 2010), even if in cortical lesions from patients with progressive MS evidence for antibody and complement-mediated demyelination is currently lacking (Brink et al., 2005). Nonetheless, it is reasonable to consider that early meningeal inflammation in MS, accompanied by the secretion of disease mediators in the subarachnoid space, could target inflammatory cells within the GM and in so doing drive disease progression.

Major differences in the pathology of meningeal infiltrates between SP MS and PP MS patients have been described, and only the correct understanding of their biology can guide future treatments. In SP MS patients, meningeal infiltrates are characterized by the presence of organized ectopic lymphoid-like follicles (tertiary lymphoid structure), which are found in close relation with GM lesions (Howell et al., 2011). Ectopic B cell follicle-like structures are found, with variable frequency, in 40\% of SP MS patients and are distributed throughout the forebrain (frequently located in the temporal, cingulate, insula and frontal cortex). These tertiary lymphoid structures within the CNS resemble secondary lymphoid organs and contain proliferating B and follicular dendritic cells (FDCs) (Aloisi and Pujol-Borrell, 2006). Importantly, the presence of B cell follicle-like structures is associated with an accompanying quantitative increase in diffuse meningeal inflammation that correlates with the degree of microglial activation and GM cortical demyelination (Howell et al., 2011). The presence of meningeal follicles is also associated with the early onset of severe cortical pathology and subsequent disease progression in many SP MS patients (Magliozzi et al., 2007).

In PP MS, substantial clusters of T cells and B cells characterize meningeal inflammatory infiltrates. However, no proliferating $\mathrm{CD}^{2} 0^{+} \mathrm{B}$ cells or FDCs - which would be suggestive of a tertiary lymphoid-like structure - can be found (Choi et al., 2012). Despite the fact that these cells do not display an organization typical of B cell follicle-like structures, meningeal infiltrates do play a critical role in PP MS as well. In fact, PP MS patients with extensive meningeal immune cell infiltration exhibit a more extensive microglial activation, demyelination and neurite loss, which is coupled with a more severe clinical course (e.g. younger age at death) (Choi et al., 2012).

It is becoming increasingly clear that inflammation in the progressive stage of MS is maintained within the CNS despite the reconstitution of the BBB (Lassmann, 2013), and therefore a focused targeting of the crosstalk between lymph follicle-like aggregates within the meninges and the cortical microglia can/will lead to successful treatments, which will hopefully preclude progressive neurodegeneration (Lassmann, 2013).

\section{Glial and neuronal damage}

\subsection{Demyelination}

Oligodendrocytes are specialized glial cells that provide support and insulation to neurons in the CNS by wrapping lipidrich concentric membranes (myelin sheaths) on axons via proteinprotein interactions (Hauser and Oksenberg, 2006). Major myelin proteins include proteolipid protein ( $\sim 50 \%$ of the total), a group of myelin basic protein isoforms ( $\sim 30 \%$ of the total), and minor proteins such as MOG, CNPase, MAG, that as a whole represent less than $1 \%$ of the total (Cuzner and Norton, 1996). Beyond trophic support, myelin sheaths alter the electrical properties of the axon, creating regions of high resistance and low capacitance, thereby facilitating rapid saltatory propagation of nerve impulses between regions of the exposed axolemma (nodes of Ranvier) (Irvine and Blakemore, 2008; Waxman and Ritchie, 1993). When myelin or myelin forming cells are damaged by the autoimmune inflammatory response, both the support and the insulation of axons is compromised, thus leading to deficits in neuronal function that can be reversible (i.e. conduction block) or permanent.

Distinct mechanisms that drive the initial demyelination have been described within the different lesional patterns of MS. While in lesional patterns I and II demyelination is trigged primarily via the damage of myelin sheaths, in lesional patterns III and IV the death of the oligodendrocytes themselves represents the key driver of disease pathogenesis (Lucchinetti et al., 2000).

Direct damage of myelin sheaths may depend on the release of toxic factors (e.g. TNF- $\alpha$, nitric oxide) produced by activated macrophages (Bitsch et al., 2000; Hofman et al., 1989; Selmaj et al., 1991), or by humoral immunity (Genain et al., 1999; Lucchinetti et al., 2000). The role of serum autoantibodies has gained much attention in MS research and there are clear therapeutic repercussions in selected groups of patients. It has been described that one third of MS patients develop autoantibodies; of note, these autoantibodies are more frequently detected in RR MS cases (acute steroid resistant relapses) than in PP MS patients (Elliott et al., 2012). Moreover, it has been described that lesional pattern II MS patients are more likely to respond favorably to plasma exchange as compared to lesional patterns I or III (Keegan et al., 2005). The antigen specificity of these autoantibodies has yet to be established. One of the most promising candidates in MS was the MOG (Genain et al., 1999). Anti-MOG antibodies have been described in MS lesions (Genain et al., 1999) and elevated antibody titers against MOG were also reported in the serum and CSF of MS patients (Reindl et al., 1999). However, it is now clear that MOGspecific autoantibodies are common to a series of human demyelinating disorders, including pediatric cases of MS, acute disseminated encephalomyelitis (ADEM), optic neuritis (Willison and Linington, 2012) and may even be present within healthy controls (Lampasona et al., 2004). The lack of specificity of antiMOG antibodies has recently been balanced by a report indicating that the MOG index, which indicates the level of antibodies to MOG within the CNS, does seem to be a promising diagnostic tool and a marker of disease progression (Klawiter et al., 2010).

Recently, heteromeric complexes containing the myelinderived lipids sulfatides have been identified as prominent targets of oligoclonal band antibodies in MS (Brennan et al., 2011). The use of a 'combinatorial glycomic' approach to study glycolipid and lipid complexes has permitted the isolation of molecular structures capable of mimicking the in vivo antigenicity of the putative targets of MS oligoclonal bands (Galban-Horcajo et al., 2014; Rinaldi et al., 2012). As a result of this (and other) elegant work, novel autoantibody targets in MS are likely to emerge.

The primary death of oligodendrocytes is a hallmark of type III and IV lesional patterns, but it is also common in other forms of oligodendrocytic damage. For example such lesional pathology has been noted in virus-induced inflammatory demyelination (Itoyama et al., 1982) and in early CNS lesions secondary to an ischemic/hypoxic mechanisms of injury (Aboul-Enein et al., 2003; Ludwin and Johnson, 1981). While the type IV pattern is very rare (the most probable mechanism of action driving this degenerative pattern is the release of toxic factors by activated macrophages) (Lucchinetti et al., 2000), demyelination in the type III pattern seems to be linked to a failure in mitochondrial activity that causes the death of oligodendrocytes (e.g. via the release of pro-apoptotic factors), while concurrently disrupting the differentiation of oligodendrocytes precursor cells (OPCs) (Ziabreva et al., 2010). The mitochondrial proteins that are likely most affected in these lesions are cytochrome $C$ oxidase-I, which is essential for the activity of the mitochondrial respiratory chain complex IV, and the cytochrome C oxidase-IV, which is important for the assembly and the stability of complex IV (Mahad et al., 2008). Mitochondrial injury can be triggered by reactive oxygen species and nitric oxide, 
which are released by activated microglia via the classical NADPH oxidase 2 burst (Fischer et al., 2012). Enhanced levels of key subunits of NADPH oxidase type 2 (gb91phox, p22phox) are observed in the activated microglia of these lesions, thus indicating the assembly of a functional NADPH oxidase 2 complex (Fischer et al., 2012). Type III pattern lesions are also characterized by a reduced number of differentiated macrophages expressing CC chemokine receptor (CCR)-5 and by an increased number of undifferentiated macrophages expressing CCR1 (Mahad et al., 2004), which both support hypoxia-dependent demyelination. In fact, the transcription factor hypoxia-inducible factor $1-\alpha$ has been found in MS type III lesions and it is likely to bind regulatory elements that increase CCR1 expression (Aboul-Enein et al., 2003; Scotton et al., 2001).

Understanding the mechanisms that drive demyelination in different pathological settings is fundamental to the development of targeted therapies for each patient in each stage of disease.

\subsection{Neurodegeneration}

While the immune-mediated destruction of CNS myelin and oligodendrocytes have traditionally been considered the primary pathologic drivers of MS, progressive GM damage is now considered to be one of the major causes of irreversible neurological disability in MS patients. Cortical damage in MS can occur via an indirect route, which is driven by neuronal loss induced by retrograde degeneration from WM lesions, or as a direct consequence of the localization of demyelinated plaques within the cortex.

Early descriptions of MS pathology emphasized the functional importance of axonal destruction induced by inflammatory WM lesions, which in turn led to secondary (Wallerian) tract degeneration and global brain atrophy (Kornek and Lassmann, 1999). It has been described that the formation of new cortical lesions is more likely to occur in cortical areas that were previously connected with sites of previous damage in the WM (Kolasinski et al., 2012), and axonal degeneration has been identified as the major determinant of irreversible neurological disability in the progressive phase of MS. While this process may remain clinically silent for many years, irreversible neurological disability ensues as compensatory CNS resources are exhausted and neurodegenerative mechanisms triggered (Bjartmar et al., 2003). Understanding the mechanisms that mediate axonal loss in MS is therefore fundamental to unraveling pathways of disease progression.

Oligodendrocytes provide axonal insulation and trophic support that are essential for long-term axonal survival (Nave, 2010). Following demyelination, $\mathrm{Na}^{+}$channels that are normally located at the nodes of Ranvier become diffusely distributed along the axolemma. In conditions of reduced axoplasmic ATP production (similar to those present in inflammatory WM lesions), the $\mathrm{Na}^{+} / \mathrm{K}^{+}$ATPase pump that normally exchanges $\mathrm{Na}^{+}$for extracellular $\mathrm{K}^{+}$after depolarization is impaired. In its place the $\mathrm{Na}^{+} / \mathrm{Ca}^{++}$ exchanger, which exchanges axoplasmic $\mathrm{Ca}^{++}$for extracellular $\mathrm{Na}^{+}$, will reverse its activity leading to axonal increase of $\mathrm{Ca}^{++}$and subsequently $\mathrm{Ca}^{++}$mediated degenerative responses (Smith, 2007; Waxman, 2006). Excessive axoplasmic $\mathrm{Ca}^{++}$accumulation causes a vicious cycle of impaired mitochondrial function, reduced energy production and compromised axonal transport that further propagates damage (Mahad et al., 2008). This imbalance between increased energy demand and decreased energy supply has been termed virtual hypoxia and eventually leads to degeneration of the axon in the WM (Lassmann, 2003; Trapp and Stys, 2009).

Formation of axonal ovoids is a pathologic hallmark of transected axons, which is normally accompanied by a dramatic increase in non-phosphorylated neurofilament epitopes (Trapp et al., 1998) and axonal accumulation of amyloid precursor protein (Ferguson et al., 1997). In acute MS lesions, the terminal axonal ovoids are often surrounded by macrophages and activated microglia that release a plethora of substances, including proteolytic enzymes, cytokines, oxidative products and free radicals, which can further damage axons (Nave and Trapp, 2008). Activated immune cells and astrocytes are also a major sources of glutamate in acute MS lesions and can damage oligodendrocytes, myelin and axons (Matute et al., 2001) by activating their ionotropic and metabotropic receptors (Geurts et al., 2003).

Histopathological studies have shown that cortical demyelination can occur without any obvious anatomical relationships to diffuse or focal WM changes (Bo et al., 2007). Microarray studies performed on the cortical tissue of MS patients shed light on the potential mechanisms underlying the direct damage of cortical neurons. A study on samples of non-demyelinated cortex revealed that nuclear-encoded mitochondrial genes, and the functional activities of the mitochondrial respiratory chain complexes I and III, were decreased in MS patients (Dutta et al., 2006). Consistently, a recent gene expression study on actively demyelinating subpial cortical lesions supported the idea that oxidative injury may be one of the major driving forces of cortical demyelination (Fischer et al., 2013). Interestingly, more than $80 \%$ of the identified MS-specific genes were related to $\mathrm{T}$ cell-mediated inflammation, microglia activation and oxidative injury, thus suggesting strong relationships among these processes.

The profound oxidative injury observed in MS lesions seems to be related to mitochondrial impairment in damaged axons (Murphy, 2009). This mitochondrial dysfunction is probably caused by free oxygen radicals, which are produced during inflammation in the WM but also via the dysfunctional mitochondria themselves (Fischer et al., 2012). This mechanism is amplified by the massive liberation of iron from oligodendrocytes and neurons (Hametner et al., 2013) and the expression of NADPH oxidase in microglia, as has been previously described (Fischer et al., 2012). Changes related to mitochondrial function are also found to be associated with an alteration of genes related to axonal transport and synaptic function, thus suggesting a relationship between reduced metabolism and reduced innervation (Dutta et al., 2011). Consistently, synaptic loss is a characteristic feature of GM lesions (particularly in type I lesions) (Wegner et al., 2006), and neurite density is proportionally reduced with increased meningeal inflammation (Choi et al., 2012).

Whether these mechanisms are a deleterious consequence of the inflammatory disease or whether they are part of a neuroprotective response of cortical neurons has yet to be clarified (Dutta and Trapp, 2011). It is plausible to think that a combination of both indirect and direct causes, serve to induce cortical degeneration and ultimately GM pathology. A unifying hypothesis suggests that distant WM inflammation can induce a retrograde neurodegeneration that leads to microglia activation within the cortex (Lassmann, 2012; Perry et al., 2010). These pre-activated microglial cells are more easily converted into a cytotoxic phenotype when exposed to pro-inflammatory molecules and start to release mediators (e.g. reactive oxygen species or nitric oxide) that favor the imbalance between energy demand and energy supply in chronically demyelinated axons.

\section{Mechanisms of tissue repair and regeneration}

\subsection{Remyelination}

Spontaneous remyelination is a process in which oligodendrocytes and OPCs attempt to re-ensheath demyelinated axons 
(Smith et al., 1979). Clearly, remyelination is a highly regulated process that requires multiple steps to be efficiently completed and, as such, the failure of remyelination is a common finding in MS pathology.

In the early stages of the illness, remyelination occurs in MS lesions via repeated cycles of de- and re-myelination, which in turn lead to a myelin sheath that is both thinner/shorter than normal (Ludwin and Maitland, 1984). These early remyelinating lesions are characterized by a significant increase in the number of oligodendrocyte transcription factor (Olig) $2^{+}$OPCs (Kuhlmann et al., 2008), which are distributed along an increasing gradient from the core to the periphery of the lesion (Kuhlmann et al., 2008; Moll et al., 2013). Although it has been shown that the majority of these lesions display a very low number of mature oligodendrocytes after damage (Lucchinetti et al., 1999), a certain degree of remyelination does occur in early MS lesions and up to a third of the OPCs transition to $\mathrm{NogoA}^{+}$mature oligodendrocytes in vivo (Kuhlmann et al., 2008). Post-mortem studies have also come to suggest that the extent of remyelination is in part related to the location of the lesions, as deep WM and subcortical lesions are more likely to be completely remyelinated than those lesions localized in proximity of the periventricular areas (Patrikios et al., 2006).

In chronic MS, the limited capacity for spontaneous remyelination is even more pronounced (Antel et al., 2012). Maturing OPCs are rarely present in chronic MS lesions of the WM, thus suggesting a block in the differentiation of OPCs as the major determinant of remyelination failure. The reasons behind this progressive reduction of remyelinating ability throughout the disease course are not fully understood. However, it is reasonable to speculate that the altered and less efficient inflammatory responses in chronic MS might be the cause of the witnessed different extent of remyelination (Kuhlmann et al., 2008). In fact, the previously described slowly expanding lesions (characteristic of progressive MS) may be linked to impaired clearance of myelin debris, which constitute inhibitory cues serving to disrupt remyelination in the chronic phases of the disease process (Bramow et al., 2010; Miron and Franklin, 2014). Despite the critical role played by inflammation in the pathogenesis of the disease, it appears that one of the main determinants for proficient remyelination and enhancement of reparative processes in the $\mathrm{WM}$ is in fact the effective activation of the immune system (Peruzzotti-Jametti et al., 2014). Of note, failure of remyelination within the GM is likely to be at least in part, due to other mechanisms. For example, post-mortem studies on patients with progressive MS have revealed that the density of OPCs and premyelinating oligodendrocytes is not decreased in cortical lesions (Chang et al., 2002), and this is likely due to a more permissive microenvironment for OPCs within the cortex (e.g. less extracellular matrix molecules and less astrogliosis), as later described (Chang et al., 2012).

On a cellular/molecular level, failure in myelin repair is linked to (i) inadequate activation, (ii) inefficient recruitment and/or (iii) lack of differentiation of OPCs (Franklin and Gallo, 2014). While OPC activation relies on the re-expression of certain developmental genes (e.g. the transcription factors Olig1 or Olig2) that are expressed during early myelinogenesis (Arnett et al., 2004; Kim et al., 2011), OPC recruitment is ultimately affected by the presence of inhibitory cues. Accumulation of the extracellular matrix glycoprotein anosimin-1 (Clemente et al., 2011), increase in fibronectin (Stoffels et al., 2013) and hyaluronan (Back et al., 2005) are all inhibitory for remyelination. In the CSF, soluble mediators that may affect remyelination, such as antibodies against the OPC-specific surface glycoproteins (i.e. AN2), have been described in MS patients (Niehaus et al., 2000). Within MS lesions the accumulation of inhibitory chemotaxic molecules may prevent the recruitment of OPCs to the demyelinating site. Overexpression of the chemorepulsive member of the semaphorin family, semaphorin $3 \mathrm{~A}$ has been associated with a failure of OPC recruitment (Boyd et al., 2013); and similarly, post-mortem MS studies on chronic lesions showed high expression of the chemorepulsive molecule netrin- 1 to be coupled by reduced OPC migration and differentiation (Tepavcevic et al., 2014).

OPC differentiation is composed of three different steps: (i) OPCs establish contact with an axon, (ii) they express a series of myelin-specific genes, and (iii) they ensheath the axon. All of these mechanisms are tightly regulated by the release of several of growth factors (e.g. fibroblast growth factor-2 and platelet-derived growth factor) (Murtie et al., 2005) and by the activation of specific membrane/nuclear signaling pathways. The expression of the transcription factor Sox17 is increased in active WM MS lesions, where it promotes OPC cell cycle exit and differentiation (Moll et al., 2013; Sohn et al., 2006). Similarly, Ascl-1 expression is increased at the active border of MS lesions, and guides OPC differentiation (Nakatani et al., 2013). Interestingly, the retinoid X receptor $\gamma(R X R \gamma)$, a member of the nuclear receptor superfamily that mediates signaling by 9 -cis retinoic acid (a vitamin A derivative), has been shown to drive oligodendrocyte differentiation and myelin sheath formation by OPCs (Huang and Franklin, 2012; Huang et al., 2011a,b). Being that RXR $\gamma$ is highly expressed in acute and remyelinating lesions, RXR agonists have been explored in the pathophysiologic context of MS and shown to improve remyelination in both an ex vivo culture system and in EAE animal models (Diab et al., 2004). Clinical trials evaluating RXR agonists for chronic MS are anticipated as a licensed RXR agonist, bexarotene, is already in clinical use for the treatment of cutaneous T cell lymphoma (Rodgers et al., 2013).

\subsection{Cortical regeneration}

A number of adaptive mechanisms delay (or compensate) for the neuronal degeneration in MS patients. Several functional MRI studies have identified the diffuse activation of cortical areas as a mechanism aimed at overcoming functional loss induced by MS lesions (Rocca et al., 2005). On a cellular level, neurogenesis can occur in chronic MS lesions (Chang et al., 2008) and remyelination by OPCs may account for the majority of tissue restoration (Franklin et al., 1997). Interestingly, postmortem studies on patients with progressive MS, have disclosed that remyelination is more pronounced in cortical lesions than in WM lesions. This is likely due to a more permissive environment within the cortex (i.e. less extracellular matrix molecules and less astrogliosis) for remyelination, which leads to an enhanced recruitment of OPCs.

As for WM lesions, the immune system plays a pivotal role in GM regeneration. The presence of microglia/macrophages in every step of the evolving GM lesion suggests a role for mononuclear cells in clearing the environment of growth inhibitory molecules (Piccio et al., 2007; Takahashi et al., 2007). Microglia/macrophages can indeed shape the environment by directly secreting local neurotrophic factors (e.g. brain-derived neurotrophic factor, nerve growth factor, neurotrophin-3 and oncomodulin) and indirectly stimulating (via IL-1 $\beta$ ) local CNTF production (Martino, 2004; Rawji and Yong, 2013). Interestingly, when transcriptional and translational products of CNTF-related genes were quantified in MS cortices (CNTF, CNTF receptor and downstream CNTF signaling molecules), they were found to be markedly increased in the neurons of MS patients (Dutta et al., 2007). Higher levels of CNTF were also found in the CSF of MS patients recovering from acute exacerbations (Massaro et al., 1997), thus suggesting its crucial role in both endogenous defense and regenerative mechanisms. 


\section{Therapies}

\subsection{Approved immune-modulatory treatments}

The current US Food and Drug administration (FDA) and European Medicines Agency (EMA) approved treatments for MS primarily target the underlying immunologic etiology of the disease. Approved MS-specific disease modifying treatments include injectable therapies [interferon- $\beta$ (IFN- $\beta$ ) and glatiramer acetate], oral therapies (teriflunomide, dimethyl fumarate, and fingolimod), and infusion therapies (mitoxantrone, natalizumab and alemtuzumab). The detailed effects and mechanisms of action of these drugs are summarized in Table 2.

The proximate aimof MS therapy is the reduction of clinical relapses and the decreased accumulation of nascent MRI lesions, while the overarching goal of MS therapy is to delay the evolution from a relapsing phenotype to that of a progressive phenotype. To fulfill these aims, a two-fold strategy has been widely adopted by physicians, which centers on the short-term treatment with glucocorticoids (i.e. to reduce the accumulation of disease burden after a relapse), and the long-term treatment with diseasemodifying drugs (DMDs), which prevent relapses and while possibly hindering MS progression.

\subsubsection{Glucocorticoids}

Glucocorticoids have short-term effects on the speed of functional recovery in patients with acute attacks of MS and are thus used in the treatment of acute exacerbations in RR MS patients (Berkovich, 2013). Glucocorticoids display a variety of immune modulatory mechanisms of action including, the inhibition of antigen presentation, anti-inflammatory effects (e.g. reduction of edema and arachidonic acid metabolites), a decrease in pro-inflammatory cytokine expression and the inhibition of lymphocyte proliferation (Sloka and Stefanelli, 2005). Typically, they are administered at high doses intravenously during relapse periods, without tapering post-therapy. Interestingly, a 2013 trial with a small number of patients reported that administration of bioequivalent doses of oral methylprednisolone was not inferior to intravenous methylprednisolone in terms of both the safety and efficacy profiles, measured via clinical disability and MRI activity four weeks after MS relapse (Ramo-Tello et al., 2014). However, before extension to clinical practice, these promising results must be confirmed in larger cohorts and with a more vigorous period of follow-up. Of note, long-term glucocorticoid treatment has not been proven to exert beneficial effects on the progressive stages of MS (Ciccone et al., 2008). Additionally, the extended use of glucocorticoids carries an adverse profile of side effects, which can include osteoporosis, metabolic syndrome, stomach ulcers, cataracts, and muscle weakness (Sloka and Stefanelli, 2005). Therefore, DMDs currently remain the most appealing and therapeutically efficacious drugs for the long-term treatment of RR MS patients.

\subsubsection{Disease-modifying drugs}

Options for long-term treatment of MS have undergone a rapid expansion over the last few years. In a simplified scenario, approved long-term MS therapy can now be grouped into four major categories, which depend on their presumed targets and mechanism of actions: immunomodulators (IFN- $\beta$, glatiramer acetate and dimethyl fumarate), inhibitors of immune cell trafficking (natalizumab and fingolimod), inhibitors of cell replication (teriflunomide, mitoxantrone), and those that promote immune cell depletion (alemtuzumab).

Three preparations of IFN- $\beta$ have been approved by the US FDA and have been shown to decrease clinical relapse rate and to reduce the development of new active brain lesions in RR MS (Interferon, 1995; Randomised, 1998; Jacobs et al., 1996). Of note, one of those preparations (the IFN- $\beta$ 1b) is also licensed for the treatment of SP MS patients (1998). The exact mechanisms underlying the beneficial effects of IFN- $\beta$ are likely based on the immune modulatory properties of the molecule, which include the antagonism of IFN- $\gamma$-mediated MHC up-regulation on APCs, the shift of cytokine expression to an anti-inflammatory profile, and the modulation of apoptosis. IFN- $\beta$ may also block the migration of $\mathrm{T}$ cells across the endothelium and inhibit T cell activation (DhibJalbut and Marks, 2010; Kieseier, 2011). Adverse events of IFN- $\beta$ include injection-site reactions, flu-like symptoms, leukopenia, deranged liver enzymes, and dysthyroidism.

Glatiramer acetate is a random polymer of glutamic acid, lysine, alanine and tyrosine licensed for the treatment of RR MS patients (Johnson et al., 1995). The exact mechanisms of action remain unknown but may be dependent on the induction of antigenspecific suppressor $\mathrm{T}$ cells, the inhibition of antigen presentation, the shift to an anti-inflammatory phenotype of the $\mathrm{CD}^{+} \mathrm{T}$ cell population, and/or the inhibition of myelin basic protein binding to the T cell receptor (Racke et al., 2010). Adverse events include local injection-site reactions, transient systemic post-injection reactions (i.e. chest pain, flushing, dyspnea, palpitations, and/or anxiety) and lipodystrophy (with long-term therapy).

Dimethyl fumarate (a methyl ester of fumaric acid) is an immunomodulatory agent approved for the treatment of RR MS (Fox et al., 2012a; Gold et al., 2012), that promotes a shift in cytokine production from a pro-inflammatory Th1-like pattern to an anti-inflammatory Th2 pattern, and down-regulates CNS oxidative stress by activating the nuclear factor (erythroid-derived 2)-related factor-2, a transcription factor with antioxidant properties (Albrecht et al., 2012; Scannevin et al., 2012). The most common side effects of dimethyl fumarate are flushing and gastrointestinal symptoms. Although fumaric acid has been long licensed for the treatment of psoriasis, progressive multifocal leukoencephalopathy (PML), a rare potentially fatal neurologic disease caused by reactivation of JC virus infection, has been reported in rare cases (Ermis et al., 2013; van Oosten et al., 2013).

Natalizumab is a recombinant humanized monoclonal antibody that is licensed for the treatment of RR MS (Polman et al., 2006b; Radue et al., 2010), and is currently under investigation for the treatment of progressive MS (ClinicalTrials.gov Identifier: NCT01077466 and NCT01416181). Via the blocking of $\alpha 4$-integrin binding to VCAM-1, natalizumab prevents the adhesion of leukocytes to the endothelium and their subsequent migration into the CNS (Lutterotti and Martin, 2008). This treatment is aimed at restoring (or stabilizing) the BBB by creating a normal profile of cytokine expression and blocking the transendothelial migration of activated lymphocytes (Minagar and Alexander, 2003). Natalizumab has beneficial effects on relapse rate and MRI lesion activity. Further, it has been shown to slow the progression of disability, yet it carries the risk of allergic reactions, liver toxicity, headache, fatigue and the development of PML (Langer-Gould et al., 2005). The risk of PML is increased by (i) the duration of natalizumab therapy, (ii) prior immunosuppressant treatment, and (iii) positive status with respect to anti-JC virus antibodies (Bloomgren et al., 2012).

Fingolimod is a structural analog of sphingosine, and targets sphingosine 1-phosphate receptors type 1,2,3 and 5. This molecule inhibits the sphingosine 1-phosphate signaling and strongly modulates the immune system by hindering the migration of lymphocytes from secondary lymphoid organs to the CNS, resulting in a marked decrease in the peripheral circulation and their reduced recruitment to sites of inflammation (Cohen et al., 2010). Fingolimod is approved for RR MS (Cohen et al., 2010; Kappos et al., 2010), and its efficacy in PP MS is currently being investigated (ClinicalTrials.gov Identifier: NCT00731692). The use of fingolimod is associated with bradycardia and atrioventricular 
Table 2

Disease-modifying drugs for the treatment of relapsing-remitting multiple sclerosis.

\begin{tabular}{|c|c|c|c|c|c|c|c|c|c|}
\hline Treatment & Dosage & $\begin{array}{l}\text { Route of } \\
\text { administration }\end{array}$ & $\begin{array}{l}\text { Frequency of } \\
\text { dosing }\end{array}$ & $\begin{array}{l}\text { Approval } \\
\text { (year) }\end{array}$ & Target & Mechanism of action & Effects & Side effects & References \\
\hline$I F N-\beta 1 b$ & $250 \mathrm{mcg}$ & s.c. & Every other day & 1993 & APCs, T cells & $\begin{array}{l}\text { Modulates the cytokine } \\
\text { expression profile via the } \\
\text { induction of an anti- } \\
\text { inflammatory/reduction } \\
\text { in pro-inflammatory } \\
\text { expression; blocks } \\
\text { migration of lymphocytes } \\
\text { across BBB. }\end{array}$ & $\begin{array}{l}\text { Reduced number of } \\
\text { exacerbations and } \\
\text { improved MRI measures } \\
\text { of disease activity in the } \\
\text { brains (vs placebo) }\end{array}$ & $\begin{array}{l}\text { Injection-site reactions, } \\
\text { flu-like symptoms, } \\
\text { leukopenia, deranged } \\
\text { liver enzymes, and } \\
\text { distyroidism, tolerance } \\
\text { (anti IFN antibodies) }\end{array}$ & $\begin{array}{l}\text { 1998a,b, Arnason (1993), } \\
\text { Kieseier (2011), Paty and } \\
\text { Li (1993), Goodin et al. } \\
\text { (2007) }\end{array}$ \\
\hline IFN- $\beta 1 a$ & $30 \mathrm{mcg}$ & i.m. & Once weekly & 1996 & & & & & \\
\hline IFN- $\beta$ 1a & $22-44 \mathrm{mcg}$ & s.c. & 3 times/week & 2002 & & & & & \\
\hline \multirow[t]{2}{*}{ Glatiramer Acetate } & $20 \mathrm{mg}$ & s.c. & Daily & 1996 & $\begin{array}{l}\text { APCs, } \mathrm{CD} 4^{+} \mathrm{T} \text { cells, } \\
\text { antigen-specific } \\
\text { suppressor T cells }\end{array}$ & $\begin{array}{l}\text { Modulates cytokine } \\
\text { expression profile to an } \\
\text { anti-inflammatory } \\
\text { phenotype (i.e. IL-10, TGF- } \\
\beta \text { ); induces antigen- } \\
\text { specific suppressor T cells; } \\
\text { reduces of antigen } \\
\text { presentation; corrects of } \\
\text { CD8 }{ }^{+} \text {T cell regulatory } \\
\text { deficit }\end{array}$ & $\begin{array}{l}\text { Reduced relapse rate and } \\
\text { accumulation of disability } \\
\text { (vs placebo); decrease in } \\
\text { T2 lesions }\end{array}$ & $\begin{array}{l}\text { Injection-site reactions, } \\
\text { transient systemic post- } \\
\text { injection reactions (i.e. } \\
\text { chest pain, flushing, } \\
\text { dyspnea, palpitations, } \\
\text { and/or anxiety) and } \\
\text { lipodystrophy (with long- } \\
\text { term therapy) }\end{array}$ & $\begin{array}{l}\text { Johnson et al. (1995), } \\
\text { Khan et al. (2013) }\end{array}$ \\
\hline & $40 \mathrm{mg}$ & s.c. & 3 times/week & 2014 & & & & & \\
\hline Teriflunomide & $7-14 \mathrm{mg}$ & os & Daily & 2012 & $\begin{array}{l}\text { Mitochondrial } \\
\text { DHODH }\end{array}$ & $\begin{array}{l}\text { Modulates T cell } \\
\text { responses (active } \\
\text { metabolite of } \\
\text { leflunomide) }\end{array}$ & $\begin{array}{l}\text { Reduced relapse rate, } \\
\text { disability progression and } \\
\text { MRI activity vs placebo }\end{array}$ & $\begin{array}{l}\text { Diarrhea, nausea, } \\
\text { alopecia, hair thinning, } \\
\text { and elevated alanine } \\
\text { aminotransferase levels }\end{array}$ & $\begin{array}{l}\text { Claussen and Korn (2012), } \\
\text { Confavreux et al. (2014), } \\
\text { O'Connor et al. (2011), } \\
\text { Vermersch et al. (2014) }\end{array}$ \\
\hline Dimethyl Fumarate & $240 \mathrm{mg}$ & os & Twice daily & 2013 & Nrf2 Pathway & $\begin{array}{l}\text { Activates the Nrf2- } \\
\text { dependent antioxidant } \\
\text { response }\end{array}$ & $\begin{array}{l}\text { Reduced relapse rate, } \\
\text { disability progression and } \\
\text { MRI activity (vs placebo) }\end{array}$ & $\begin{array}{l}\text { Flushing, gastrointestinal } \\
\text { symptoms, and PML (rare) }\end{array}$ & $\begin{array}{l}\text { Fox et al. (2012a), Gold } \\
\text { et al. (2012), Loma and } \\
\text { Heyman (2011) }\end{array}$ \\
\hline Natalizumab & $300 \mathrm{mg}$ & i.v. & Every 4 weeks & 2006 & $\begin{array}{l}\alpha 4 \text { subunit of } \alpha 4 \beta 1 \\
\text { VLA-4 integrin }\end{array}$ & $\begin{array}{l}\text { Prevents the migration of } \\
\text { leukocytes across the BBB } \\
\text { into the CNS }\end{array}$ & $\begin{array}{l}\text { Reduced relapse rate, } \\
\text { disability progression and } \\
\text { MRI activity vs placebo }\end{array}$ & $\begin{array}{l}\text { Allergic reactions, liver } \\
\text { toxicity, headache, fatigue } \\
\text { and PML, tolerance (anti } \\
\text { natalizumab antibodies) }\end{array}$ & $\begin{array}{l}\text { Loma and Heyman (2011), } \\
\text { Lutterotti and Martin } \\
\text { (2008), Minagar and } \\
\text { Alexander (2003), Polman } \\
\text { et al. (2006a), Radue et al. } \\
\text { (2010), Vennegoor et al. } \\
\text { (2013) }\end{array}$ \\
\hline Fingolimod & $0.5 \mathrm{mg}$ & os & Daily & 2010 & $\begin{array}{l}\text { Modulates S1P } \\
\text { receptors (type } \\
1,2,3 \text { and 5) }\end{array}$ & $\begin{array}{l}\text { Prevents CCR7 positive } \\
\text { lymphocytes, including } \\
\text { naive and central memory } \\
\text { T cells, from exiting lymph } \\
\text { nodes }\end{array}$ & $\begin{array}{l}\text { Reduced relapse rate, } \\
\text { disability progression and } \\
\text { MRI activity (vs interferon } \\
\beta \text { 1a) }\end{array}$ & $\begin{array}{l}\text { Bradycardia and } \\
\text { atrioventricular } \\
\text { conduction block during } \\
\text { initiation, risk of varicella- } \\
\text { zoster virus infections, } \\
\text { elevated liver enzymes } \\
\text { and macular edema }\end{array}$ & $\begin{array}{l}\text { Cohen et al. (2010), } \\
\text { Kappos et al. (2010), Loma } \\
\text { and Heyman (2011), } \\
\text { Schwab and Cyster (2007) }\end{array}$ \\
\hline Mitoxantrone & $12 \mathrm{mg} / \mathrm{m}^{2}$ & i.v. & Every 3 months & 2000 & Topoisomerase II & $\begin{array}{l}B \text { and } T \text { cell suppression/ } \\
\text { migration inhibition }\end{array}$ & $\begin{array}{l}\text { Reduced relapse rate, } \\
\text { disability progression and } \\
\text { MRI activity (vs placebo } \\
\text { and vs interferon } \beta \text { 1a) }\end{array}$ & $\begin{array}{l}\text { Leukemia and } \\
\text { cardiotoxicity }\end{array}$ & $\begin{array}{l}\text { Hartung et al. (2002), } \\
\text { Loma and Heyman (2011) }\end{array}$ \\
\hline
\end{tabular}


conduction block during initiation, risk of varicella-zoster virus infections, elevated liver enzymes and macular edema (Jain and Bhatti, 2012).

Teriflunomide is an active metabolite of leflunomide, approved for the treatment of RR MS (Confavreux et al., 2014; O'Connor et al., 2011; Vermersch et al., 2014). The precise mechanisms of action are not completely understood. However, it has been shown that teriflunomide inhibits mitochondrial dihydroorotate dehydrogenase, which reduces the de novo synthesis of pyrimidine nucleotides in proliferating cells. Through dihydroorotate dehydrogenase-independent mechanisms, such as the inhibition of phosphorylation of protein kinases, teriflunomide promotes an anti-inflammatory cytokine milieu and inhibits the interaction between APCs and T cells (Claussen and Korn, 2012). The most common adverse effects of teriflunomide are diarrhea, nausea, alopecia, hair thinning, and elevated alanine aminotransferase levels.

Mitoxantrone is an anthracenedione that affects DNA topoisomerase II, leading to an impairment of $\mathrm{T}$ and $\mathrm{B}$ cell proliferation (Vollmer et al., 2010). Currently, mitoxantrone is restricted to highly active patients who have failed second line treatments (lifetime cumulative dose is $<140 \mathrm{mg} / \mathrm{m}^{2}$ ) (Martinelli Boneschi et al., 2005). However, due to the high risk of leukemia ( $\sim 1 \%$ of treated patients) (Chan and Lo-Coco, 2013; Marriott et al., 2010; Martinelli et al., 2011) and of cardiotoxicity, its use in clinical practice has been progressively abandoned in favor of novel treatments, which have better therapeutic index (e.g. natalizumab, alemtuzumab).

Alemtuzumab is a humanized monoclonal antibody directed against CD52, a surface glycoprotein present on a number of mature leukocyte subpopulations, including T, B, and NK cells (Investigators et al., 2008). Binding of alemtuzumab to CD52 results in a profound complement- and antibody-dependent cellular cytotoxicity, which is followed by leukocyte reconstitution that temporally varies between leukocyte subpopulations (e.g. B cell numbers recover in approximately 6 months, whereas T cells require more than 1 year). Alemtuzumab has been recently licensed for the treatment of RR MS by the FDA and when compared to IFN- $\beta 1$ a, has shown great efficacy in reducing relapse rates, disability and MRI activity (Tuohy et al., 2015; Cohen et al., 2012; Coles et al., 2012; Investigators et al., 2008). Adverse events associated with the use of alemtuzumab are hyperacute cytokine release syndrome and the development of autoimmune diseases (i.e. Graves disease, idiopathic thrombocytopenic purpura and Goodpasture syndrome) (Clatworthy et al., 2008; Jones et al., 2009).

Currently two different strategies with regard to the long-term treatment of MS patients with DMDs have been adopted. Escalation strategy is centered on a rational therapeutic approach, in which drugs with the greatest therapeutic index (i.e. best riskbenefit ratio) are first line. If needed, drugs which are more powerful (but typically more toxic) are successively adopted (Rieckmann, 2009). Induction therapy represents a more aggressive therapeutic approach and depends instead on the use of powerful immunosuppressant drugs from the beginning (i.e. an attempt to reset the immune system) (Rieckmann, 2009). Generally speaking, patients who suffer from non-aggressive forms of RR MS are good candidates for escalation strategy, whereas those who suffer from aggressive forms of RR MS are more likely to be placed on an induction centered management strategy.

\subsubsection{Autologous hematopoietic stem cell transplantation}

The transplantation of hematopoietic stem cells (HSCs) is a widely used therapy for patients with hematopoietic malignancies and solid tumors. Autologous HSC transplantation has also been successfully used to suppress aberrant immune function in many autoimmune diseases (e.g. lupus, rheumatoid arthritis, and type 
1 diabetes). In MS patients, a graft containing HSCs is collected from the patient's bone marrow after mobilization into the circulation and collected using leukapheresis. Non-myeloablative chemotherapy and immune-depleting biological agents are then administered to ablate the autoreactive immune system. Eventually, the immune system is renewed via the infusion of previously isolated, autologous HSCs (Atkins and Freedman, 2013).

It is believed that HSC transplantation is more likely to be effective for patients with an aggressive form of MS (i.e. with profound CNS inflammation and severe clinical disability), by controlling the inflammatory response and reducing clinical relapses. In fact, following HSC transplantation in patients with aggressive SP MS, a dramatic stabilization and/or improvement of the neurological condition has been observed over a follow-up period of four years (Fagius et al., 2009; Kimiskidis et al., 2008; Mancardi et al., 2005). Of note, HSC transplantation in nonaggressive SP MS patients only induced mild clinical improvements (Chen et al., 2012; Shevchenko et al., 2012).

\subsection{Novel perspectives}

\subsubsection{Immune-modulatory therapies for progressive $M S$}

DMDs have transformed the pharmaceutical landscape and the burden of disease associated with defined subtypes of MS (i.e. RR MS). Unfortunately, such meaningful advances are still lacking for those suffering from progressive forms of the disease. While it has become increasingly clear that DMDs are effective at reducing relapses mediated by the activation of $T$ cells, they seem to have negligible effects on the primary mechanisms governing progressive tissue damage (e.g. failure of remyelination, neurodegeneration and persistent microglia/macrophage activation). As such, the results obtained from the latest phase III clinical trials with interferons (Leary et al., 2003), glatiramer acetate (Wolinsky et al., 2007), and rituximab (Hawker et al., 2009) in PP MS have yielded negative results. In line with the aforesaid, novel therapeutic approaches that interfere with the other cells of the immune system (e.g. B cells) that drive disease progression are currently undergoing clinical development.

It has been described that a single intravenous course of rituximab is capable of reducing inflammatory brain lesions and clinical relapses for 48 weeks in RR MS patients (Hauser et al., 2008). This initial observation provided definitive evidence of Bcell involvement in the pathophysiology of MS and has prompted the use of rituximab in SP MS patients as well. The ongoing RIVITaLISe trial is now testing the intravenous and intrathecal injections of rituximab in patients with SP MS (NCT01212094). The intrathecal route of administration of rituximab was chosen in an effort to target what has become increasingly recognized as compartmentalized CNS inflammation. Such focused inflammation within the context of an intact BBB (e.g. tertiary lymphoid structures) is indeed one of the major drivers of progression in chronic MS.

\subsubsection{Regenerative and neurotrophic molecules}

Promising new strategies have been shown to specifically target the failure of remyelination and the neurodegeneration typical of MS. One promising candidate is anti-LINGO-1 monoclonal antibody (BIIB033). Oligodendrocytes and neurons express LINGO-1, which regulates OPC differentiation and remyelination. MS lesions express an increased level of LINGO-1 and it has been shown that LINGO -1 antagonism enhances remyelination (Mi et al., 2013). Two separate randomized, placebo-controlled phase I studies with the BIIB033 vs. placebo (administered via intravenous infusion to 64 healthy adult volunteers and 42 subjects with RR MS or SP MS) were conducted (Tran et al., 2012). BIIB033 exhibited a favorable safety profile, and a desirable pharmacokinetics and pharmacodynamics. These findings prompted the start of a phase II clinical trial with BIIB033 (used concurrently with interferons), which is currently ongoing in patients with RR MS (ClinicalTrials.gov identifier: NCT01864148).

A second promising therapy is riluzole, which inhibits the glutamatergic activity by blocking the release of glutamate and aspartate, thereby altering the function of glutamate receptors and sodium channels (Wokke, 1996; De Jager and Hafler, 2007). Unfortunately, a phase II clinical trial on the effect of riluzole (added to weekly intramuscular IFN- $\beta$ 1a) vs. placebo in early MS provided evidence that riluzole treatment does not meaningfully reduce brain atrophy in early MS (Waubant et al., 2014). However, a phase II clinical trial on 15 patients with PP MS showed that riluzole can reduce the rate of cervical cord atrophy and the development of hypointense T1 brain lesions on MRI (Kalkers et al., 2002). Additional studies are required to unravel the therapeutic potential of these therapies for MS patients.

\subsubsection{Cellular therapies}

While it is not the aim of this review to cover drugs which are in the pre-clinical stages of development, it is nonetheless important to highlight critical pre-clinical research on MS that has led to several promising approaches shown to potentiate mechanisms of tissue recovery (Deshmukh et al., 2013; Mangas et al., 2010; Munzel and Williams, 2013; Van der Walt et al., 2010). Among these, stem cells possess a therapeutic potential that is distinct from that of small molecules and biologics. Part drug and part device, stem cells work as naturally-occurring DMDs that sense diverse signals, migrate to specific sites in the body, integrate inputs to make decisions, and execute complex response behaviors, all in the context of specific tissue microenvironments (Fischbach et al., 2013). All these attributes may be harnessed to treat a number of disease processes, including the persistent inflammation and tissue degeneration that occur in progressive MS.

However, before envisaging any potential human applications of such innovative therapies, we need to confront relevant challenges that include the identification of an ideal stem cell source for downstream transplantation.

Due to their availability and potentially beneficial properties, mesenchymal stem cells (MSCs) have been at the forefront of reparative/regenerative medicine for several diseases, including MS. In progressive MS, intravenous autologous MSC transplantation was successfully carried out in an open-label phase 2 study (Connick et al., 2012). Ten progressive MS patients were treated with a single intravenous administration of autologous bonemarrow-derived MSCs without causing serious adverse events. Beyond their safety, autologous MSCs were shown to induce an improvement in some visual endpoints that were structural (i.e. optic nerve area), functional (i.e. visual acuity) and physiological (i.e. visual evoked response latency) in nature. The neuroprotective effects of MSCs seems to be independent of directed differentiation and/or cell replacement, but rather rely on mechanisms of peripheral immunomodulation.

Of note, the use of intrathecally delivered autologous MSCs in MS has also been adopted. Although three recent reports show that intrathecally delivered MSCs are relatively safe (Karussis et al., 2010; Mohyeddin Bonab et al., 2007; Yamout et al., 2010), the authors speculate that there is a risk of treatment-related malignant neoplasm induction (Rosland et al., 2009). While important advances have been made with regard to the use of MSCs in MS, substantial challenges remain and include the nature, identity, function, mode of isolation and experimental handling of MSCs (Bianco et al., 2013).

In diseases of the CNS in which stem cell-mediated effects (i.e. bystander and tissue replacement) are desirable, the use of tissue 
specific stem cells should be promoted. Neural stem cells (NSCs) have been shown to exert remarkable trophic effects on endogenous brain cells, including endogenous myelin forming cells, and beneficial modulatory actions on innate and adaptive immune responses in mouse (Pluchino et al., 2005) and non-human primates models of MS (Martino et al., 2011; Pluchino and Cossetti, 2013; Pluchino et al., 2009).

Several phase I and II trials have been undertaken for the use of NSCs (derived from fetal allogeneic sources) in incurable CNS diseases (e.g. amyotrophic lateral sclerosis, stroke, PelizaeusMerzbacher disease, Batten's disease), but clinical trials for MS are still lacking (Chiu and Rao, 2011). Major limitations associated with the use of somatic NSCs therapies for human diseases include the source from which somatic NSCs are derived (either fetal or embryonic), the immunogenicity of the derived allogeneic graft, and the limited expandability/genotypic stability over extensive passaging in vitro. As such, risks of transplant rejection (Fox et al., 2012b; Pearl et al., 2012), and key ethical controversies (RamosZuniga et al., 2012) have prevented the translation of NSC therapy into the clinic.

The generation of induced pluripotent stem cells (iPSCs) from adult skin fibroblasts has heralded the possibility of autologous transplants that would circumvent histocompatibility barriers. iPSCs are pluripotent stem cells with molecular and functional properties similar to embryonic stem cells that can be isolated from the very same patient and differentiated toward multipotent tissue specific cells. While iPSC technology displays tremendous promise with regard to regenerative medicine, the field of cellular reprogramming is one that is still developing. As such, the dedifferentiation of somatic cells into pluripotent cells comes with an intrinsic set of limitations. These include major difficulties in obtaining differentiation into specific lineages and the requirement of extensive passaging in vitro (Fong et al., 2010). Further, one cannot exclude the possibility of remaining neoplastic pluripotent cells in the final medical product (Liang and Zhang, 2013).

Advances in the direct conversion (transdifferentiation) of somatic cells into multipotent/stably expandable induced NSCs (iNSCs) may overcome histocompatibility barriers and avoid extensive in vitro manipulation (Thier et al., 2012). The iNSCs obtained from skin fibroblasts are stably expandable, tissue specific, display unlimited self-renewal and can be differentiated in vitro giving rise to multiple subtypes of neurons, astrocytes and oligodendrocytes. Compared with the circuitous two-step strategy used during the conversion of somatic cells to iPSCs (and subsequent differentiation into neural stem cells), the relatively straightforward reprogramming of iNSCs is highly efficient, direct and safe. While the generation of human iNSCs has been already achieved, future experiments will be necessary to help define the potential of these cells in the context of immunomodulation and/or tissue trophism inMS.

Of note, a recent open-label, phase I clinical trial designed to evaluate the safety and tolerability of intrathecal administration of autologous MSCs-derived NSCs could represent a groundbreaking approach to the treatment of progressive MS (NCT01933802). These MSCs-derived NSCs display a reduced expression of mesodermal markers and reduced capacity for adipogenic or osteogenic differentiation that may reduce the potential of unwanted mesodermal differentiation upon CNS transplantation (Harris et al., 2012), while concurrently maintaining many of the advantages displayed by both MSCs and NSCs.

\section{Conclusions}

Recent scientific and clinical work has provided key insights into the pathogenesis of the diverse spectrum of lesions in MS patients. Although the pathogenesis of MS remains an active area of investigation, understanding the salient features that drive the evolution of MS lesions in different brain regions (space) during diverse disease phases (time), will help to develop future therapeutic approaches.

Further work is needed to define what are the exact immunological and neurobiological mechanisms underlying the heterogeneous patterns of MS lesional pathology and whether patients suffering from certain subtypes of disease would require unique combinations of therapy. Ultimately, a comprehensive understanding of the definitive nature, location and cellular makeup of MS lesions will allow the translation of relevant biological targets into clinical significant therapies for patients in need.

\section{Conflicts of interest}

The authors declare no conflicts of financial interest.

\section{Acknowledgments}

The authors thank Dr. Gillian Tannahill and Prof. Alasdair Coles for critically reviewing the article, and Prof. Kenneth J Smith for the illuminating discussions on MS pathophysiology. We acknowledge the contribution of past and present members of Pluchino laboratory, who have contributed to (or inspired) this manuscript.

Research in the author's laboratory is supported by the National Multiple Sclerosis Society (NMSS; RG-4001-A1), the Italian Multiple Sclerosis Foundation (FISM; RG 2010/R/31), the Italian Ministry of Health (GR08/7) the European Research Council (ERC) 2010-StG (RG 260511-SEM_SEM), the European Community (EC) 7th Framework Program (FP7/2007-2013; RG 280772-iONE), The Evelyn Trust (RG 69865), The Bascule Charitable Trust (RG 75149), The Great Britain Sakakawa Foundation and a core support grant from the Wellcome Trust and MRC to the Wellcome Trust Medical Research Council Cambridge Stem Cell Institute. GM was supported by an European Neurological Society (ENS) Training fellowship. LPJ was supported by the Wellcome Trust [RRZA/057 RG79423]. JDB was supported by a NIH-OxCam fellowship.

\section{References}

Abbas, A.K., Murphy, K.M., Sher, A., 1996. Functional diversity of helper T lymphocytes. Nature 383, 787-793.

Aboul-Enein, F., Rauschka, H., Kornek, B., Stadelmann, C., Stefferl, A., Bruck, W., Lucchinetti, C., Schmidbauer, M., Jellinger, K., Lassmann, H., 2003. Preferential loss of myelin-associated glycoprotein reflects hypoxia-like white matter damage in stroke and inflammatory brain diseases. J. Neuropathol. Exp. Neurol. 62 25-33.

Adams, C.W., Poston, R.N., Buk, S.J., 1989. Pathology, histochemistry and immunocytochemistry of lesions in acute multiple sclerosis. J. Neurol. Sci. 92, 291-306.

Agrawal, S., Anderson, P., Durbeej, M., van Rooijen, N., Ivars, F., Opdenakker, G., Sorokin, L.M., 2006. Dystroglycan is selectively cleaved at the parenchymal basement membrane at sites of leukocyte extravasation in experimental autoimmune encephalomyelitis. J. Exp. Med. 203, 1007-1019.

Albrecht, P., Bouchachia, I., Goebels, N., Henke, N., Hofstetter, H.H., Issberner, A., Kovacs, Z., Lewerenz, J., Lisak, D., Maher, P., Mausberg, A.K., Quasthoff, K., Zimmermann, C., Hartung, H.P., Methner, A., 2012. Effects of dimethyl fumarate on neuroprotection and immunomodulation. J. Neuroinflamm. 9, 163.

Aloisi, F., 2001. Immune function of microglia. Glia 36, 165-179.

Aloisi, F., Pujol-Borrell, R., 2006. Lymphoid neogenesis in chronic inflammatory diseases. Nat. Rev. Immunol. 6, 205-217.

Antel, J., Antel, S., Caramanos, Z., Arnold, D.L., Kuhlmann, T., 2012. Primary progressive multiple sclerosis: part of the MS disease spectrum or separate disease entity? Acta Neuropathol. (Berl.) 123, 627-638.

Arnason, B.G., 1993. Interferon beta in multiple sclerosis. Neurology 43, 641-643.

Arnett, H.A., Fancy, S.P., Alberta, J.A., Zhao, C., Plant, S.R., Kaing, S., Raine, C.S Rowitch, D.H., Franklin, R.J., Stiles, C.D., 2004. bHLH transcription factor Olig1 is required to repair demyelinated lesions in the CNS. Science 306, 2111-2115.

Ascherio, A., Munger, K.L., 2007a. Environmental risk factors for multiple sclerosis. Part I: The role of infection. Ann Neurol 61, 288-299.

Ascherio, A., Munger, K.L., 2007b. Environmental risk factors for multiple sclerosis. Part II: Noninfectious factors. Ann. Neurol. 61, 504-513. 
Ascherio, A., Munger, K.L., White, R., Kochert, K., Simon, K.C., Polman, C.H., Freedman, M.S., Hartung, H.P., Miller, D.H., Montalban, X., Edan, G., Barkhof, F., Pleimes, D., Radu, E.W., Sandbrink, R., Kappos, L., Pohl, C., 2014. Vitamin D as an early predictor of multiple sclerosis activity and progression. JAMA Neurol. 71, 306-314.

Atkins, H.L., Freedman, M.S., 2013. Hematopoietic stem cell therapy for multiple sclerosis: top 10 lessons learned. Neurotherapeutics 10, 68-76.

Back, S.A., Tuohy, T.M., Chen, H., Wallingford, N., Craig, A., Struve, J., Luo, N.L., Banine, F., Liu, Y., Chang, A., Trapp, B.D., Bebo Jr., B.F., Rao, M.S., Sherman, L.S., 2005. Hyaluronan accumulates in demyelinated lesions and inhibits oligodendrocyte progenitor maturation. Nat. Med. 11, 966-972.

Barkhof, F., Filippi, M., Miller, D.H., Scheltens, P., Campi, A., Polman, C.H., Comi, G. Ader, H.J., Losseff, N., Valk, J., 1997. Comparison of MRI criteria at first presentation to predict conversion to clinically definite multiple sclerosis. Brain 120 (Pt 11), 2059-2069.

Berkovich, R., 2013. Treatment of acute relapses in multiple sclerosis. Neurotherapeutics 10, 97-105.

Bianco, P., Cao, X., Frenette, P.S., Mao, J.J., Robey, P.G., Simmons, P.J., Wang, C.Y., 2013. The meaning, the sense and the significance: translating the science of mesenchymal stem cells into medicine. Nat. Med. 19, 35-42.

Biswas, S.K., Mantovani, A., 2010. Macrophage plasticity and interaction with lymphocyte subsets: cancer as a paradigm. Nat. Immunol. 11, 889-896.

Bitsch, A., Kuhlmann, T., Da Costa, C., Bunkowski, S., Polak, T., Bruck, W., 2000 Tumour necrosis factor alpha mRNA expression in early multiple sclerosis lesions: correlation with demyelinating activity and oligodendrocyte pathology. Glia 29, 366-375.

Bjartmar, C., Wujek, J.R., Trapp, B.D., 2003. Axonal loss in the pathology of MS: consequences for understanding the progressive phase of the disease. J. Neurol. Sci. 206, 165-171.

Bloomgren, G., Richman, S., Hotermans, C., Subramanyam, M., Goelz, S., Natarajan, A., Lee, S., Plavina, T., Scanlon, J.V., Sandrock, A., Bozic, C., 2012. Risk of natalizumab-associated progressive multifocal leukoencephalopathy. N. Engl. J. Med. 366, 1870-1880.

Bo, L., Vedeler, C.A., Nyland, H., Trapp, B.D., Mork, S.J., 2003a. Intracortical multiple sclerosis lesions are not associated with increased lymphocyte infiltration. Mult. Scler. 9, 323-331.

Bo, L., Vedeler, C.A., Nyland, H.I., Trapp, B.D., Mork, S.J., 2003b. Subpial demyelination in the cerebral cortex of multiple sclerosis patients. J. Neuropathol. Exp. Neurol. 62, 723-732

Bo, L., Geurts, J.J., van der Valk, P., Polman, C., Barkhof, F., 2007. Lack of correlation between cortical demyelination and white matter pathologic changes in multiple sclerosis. Arch. Neurol. 64, 76-80.

Boyd, A., Zhang, H., Williams, A., 2013. Insufficient OPC migration into demyelinated lesions is a cause of poor remyelination in MS and mouse models. Acta Neuropathol. (Berl.) 125, 841-859.

Bramow, S., Frischer, J.M., Lassmann, H., Koch-Henriksen, N., Lucchinetti, C.F. Sorensen, P.S., Laursen, H., 2010. Demyelination versus remyelination in progressive multiple sclerosis. Brain 133, 2983-2998.

Breij, E.C., Brink, B.P., Veerhuis, R., van den Berg, C., Vloet, R., Yan, R., Dijkstra, C.D. van der Valk, P., Bo, L., 2008. Homogeneity of active demyelinating lesions in established multiple sclerosis. Ann. Neurol. 63, 16-25.

Brennan, K.M., Galban-Horcajo, F., Rinaldi, S., O’Leary, C.P., Goodyear, C.S., Kalna, G., Arthur, A., Elliot, C., Barnett, S., Linington, C., Bennett, J.L., Owens, G.P., Willison, H.J., 2011. Lipid arrays identify myelin-derived lipids and lipid complexes as prominent targets for oligoclonal band antibodies in multiple sclerosis. J. Neuroimmunol. 238, 87-95.

Brink, B.P., Veerhuis, R., Breij, E.C., van der Valk, P., Dijkstra, C.D., Bo, L., 2005. The pathology of multiple sclerosis is location-dependent: no significant complement activation is detected in purely cortical lesions. J. Neuropathol. Exp. Neurol. 64, 147-155.

Brownell, B., Hughes, J.T., 1962. The distribution of plaques in the cerebrum in multiple sclerosis. J. Neurol. Neurosurg. Psychiatry 25, 315-320.

Bruck, W., Sommermeier, N., Bergmann, M., Zettl, U., Goebel, H.H., Kretzschmar, H.A., Lassmann, H., 1996. Macrophages in multiple sclerosis. Immunobiology 195, 588-600.

Calabrese, M., Gallo, P., 2009. Magnetic resonance evidence of cortical onset of multiple sclerosis. Mult. Scler. 15, 933-941.

Calabrese, M., De Stefano, N., Atzori, M., Bernardi, V., Mattisi, I., Barachino, L., Morra, A., Rinaldi, L., Romualdi, C., Perini, P., Battistin, L., Gallo, P., 2007. Detection of cortical inflammatory lesions by double inversion recovery magnetic resonance imaging in patients with multiple sclerosis. Arch. Neurol. 64, 1416-1422.

Calabrese, M., Agosta, F., Rinaldi, F., Mattisi, I., Grossi, P., Favaretto, A., Atzori, M. Bernardi, V., Barachino, L., Rinaldi, L., Perini, P., Gallo, P., Filippi, M., 2009. Cortical lesions and atrophy associated with cognitive impairment in relapsing-remitting multiple sclerosis. Arch. Neurol. 66, 1144-1150.

Calabrese, M., Grossi, P., Favaretto, A., Romualdi, C., Atzori, M., Rinaldi, F., Perini, P., Saladini, M., Gallo, P., 2012a. Cortical pathology in multiple sclerosis patients with epilepsy: a 3 year longitudinal study. J. Neurol. Neurosurg. Psychiatry 83 49-54.

Calabrese, M., Poretto, V., Favaretto, A., Alessio, S., Bernardi, V., Romualdi, C., Rinaldi, F., Perini, P., Gallo, P., 2012b. Cortical lesion load associates with progression of disability in multiple sclerosis. Brain 135, 2952-2961.

Calabrese, M., Favaretto, A., Martini, V., Gallo, P., 2013. Grey matter lesions in MS: from histology to clinical implications. Prion 7, 20-27.

Chabas, D., Baranzini, S.E., Mitchell, D., Bernard, C.C., Rittling, S.R., Denhardt, D.T., Sobel, R.A., Lock, C., Karpuj, M., Pedotti, R., Heller, R., Oksenberg, J.R., Steinman,
L., 2001. The influence of the proinflammatory cytokine, osteopontin, on autoimmune demyelinating disease. Science 294, 1731-1735.

Chan, A., Lo-Coco, F., 2013. Mitoxantrone-related acute leukemia in MS: an open or closed book? Neurology 80, 1529-1533

Chang, A., Tourtellotte, W.W., Rudick, R., Trapp, B.D., 2002. Premyelinating oligodendrocytes in chronic lesions of multiple sclerosis. N. Engl. J. Med. 346, 165-173.

Chang, A., Smith, M.C., Yin, X., Fox, R.J., Staugaitis, S.M., Trapp, B.D., 2008. Neurogenesis in the chronic lesions of multiple sclerosis. Brain 131, 2366-2375.

Chang, A., Staugaitis, S.M., Dutta, R., Batt, C.E., Easley, K.E., Chomyk, A.M., Yong, V.W., Fox, R.J., Kidd, G.J., Trapp, B.D., 2012. Cortical remyelination: a new target for repair therapies in multiple sclerosis. Ann. Neurol. 72, 918-926.

Charcot, J., 1848. Histologie de la sclérose en plaques. Gaz. Hop. Civ. Mil. 41, 554-566.

Chen, B., Zhou, M., Ouyang, J., Zhou, R., Xu, J., Zhang, Q., Yang, Y., Xu, Y., Shao, X., Meng, L., Wang, J., Xu, Y., Ni, X., Zhang, X., 2012. Long-term efficacy of autologous haematopoietic stem cell transplantation in multiple sclerosis at a single institution in China. Neurol. Sci. 33, 881-886.

Chiaravalloti, N.D., DeLuca, J., 2008. Cognitive impairment in multiple sclerosis. Lancet Neurol. 7, 1139-1151.

Chiu, A.Y., Rao, M.S., 2011. Cell-based therapy for neural disorders - anticipating challenges. Neurotherapeutics 8, 744-752

Choi, S.R., Howell, O.W., Carassiti, D., Magliozzi, R., Gveric, D., Muraro, P.A., Nicholas, R., Roncaroli, F., Reynolds, R., 2012. Meningeal inflammation plays a role in the pathology of primary progressive multiple sclerosis. Brain 135, 2925-2937.

Ciccone, A., Beretta, S., Brusaferri, F., Galea, I., Protti, A., Spreafico, C., 2008. Corticosteroids for the long-term treatment in multiple sclerosis. Cochrane Database Syst. Rev. CD006264.

Clatworthy, M.R., Wallin, E.F., Jayne, D.R., 2008. Anti-glomerular basement membrane disease after alemtuzumab. N. Engl. J. Med. 359, 768-769.

Claussen, M.C., Korn, T., 2012. Immune mechanisms of new therapeutic strategies in MS: teriflunomide. Clin. Immunol. 142, 49-56.

Clemente, D., Ortega, M.C., Arenzana, F.J., de Castro, F., 2011. FGF-2 and Anosmin-1 are selectively expressed in different types of multiple sclerosis lesions. J. Neurosci. 31, 14899-14909.

Cohen, J.A., Barkhof, F., Comi, G., Hartung, H.P., Khatri, B.O., Montalban, X., Pelletier, J., Capra, R., Gallo, P., Izquierdo, G., Tiel-Wilck, K., de Vera, A., Jin, J., Stites, T., Wu, S., Aradhye, S., Kappos, L., Group, T.S., 2010. Oral fingolimod or intramuscular interferon for relapsing multiple sclerosis. N. Engl. J. Med. 362, 402-415.

Cohen, J.A., Coles, A.J., Arnold, D.L., Confavreux, C., Fox, E.J., Hartung, H.P., Havrdova, E., Selmaj, K.W., Weiner, H.L., Fisher, E., Brinar, V.V., Giovannoni, G., Stojanovic, M., Ertik, B.I., Lake, S.L., Margolin, D.H., Panzara, M.A., Compston, D.A., investigators, C.-M.I., 2012. Alemtuzumab versus interferon beta 1a as first-line treatment for patients with relapsing-remitting multiple sclerosis: a randomised controlled phase 3 trial. Lancet 380, 1819-1828.

Coles, A.J., Twyman, C.L., Arnold, D.L., Cohen, J.A., Confavreux, C., Fox, E.J., Hartung, H.P., Havrdova, E., Selmaj, K.W., Weiner, H.L., Miller, T., Fisher, E., Sandbrink, R., Lake, S.L., Margolin, D.H., Oyuela, P., Panzara, M.A., Compston, D.A., investigators, C.-M.I., 2012. Alemtuzumab for patients with relapsing multiple sclerosis after disease-modifying therapy: a randomised controlled phase 3 trial. Lancet 380, 1829-1839.

Compston, A., Coles, A., 2002. Multiple sclerosis. Lancet 359, 1221-1231.

Compston, A., Coles, A., 2008. Multiple sclerosis. Lancet 372, 1502-1517.

Confavreux, C., Aimard, G., Devic, M., 1980. Course and prognosis of multiple sclerosis assessed by the computerized data processing of 349 patients. Brain 103, 281-300.

Confavreux, C., O’Connor, P., Comi, G., Freedman, M.S., Miller, A.E., Olsson, T.P., Wolinsky, J.S., Bagulho, T., Delhay, J.L., Dukovic, D., Truffinet, P., Kappos, L., Group, T.T., 2014. Oral teriflunomide for patients with relapsing multiple sclerosis (TOWER): a randomised, double-blind, placebo-controlled, phase 3 trial. Lancet Neurol. 13, 247-256.

Connick, P., Kolappan, M., Crawley, C., Webber, D.J., Patani, R., Michell, A.W., Du, M.Q., Luan, S.L., Altmann, D.R., Thompson, A.J., Compston, A., Scott, M.A., Miller, D.H., Chandran, S., 2012. Autologous mesenchymal stem cells for the treatment of secondary progressive multiple sclerosis: an open-label phase 2a proof-ofconcept study. Lancet Neurol. 11, 150-156.

Correale, J., Ysrraelit, M.C., Gaitan, M.I., 2009. Immunomodulatory effects of Vitamin D in multiple sclerosis. Brain 132, 1146-1160.

Cuzner, M.L., Norton, W.T., 1996. Biochemistry of demyelination. Brain Pathol. 6, 231-242.

De Groot, C.J., Bergers, E., Kamphorst, W., Ravid, R., Polman, C.H., Barkhof, F., van der Valk, P., 2001. Post-mortem MRI-guided sampling of multiple sclerosis brain lesions: increased yield of active demyelinating and (p)reactive lesions. Brain $124,1635-1645$

De Jager, P.L., Hafler, D.A., 2007. New therapeutic approaches for multiple sclerosis. Annu. Rev. Med. 58, 417-432.

Deshmukh, V.A., Tardif, V., Lyssiotis, C.A., Green, C.C., Kerman, B., Kim, H.J., Padmanabhan, K., Swoboda, J.G., Ahmad, I., Kondo, T., Gage, F.H., Theofilopoulos, A.N., Lawson, B.R., Schultz, P.G., Lairson, L.L., 2013. A regenerative approach to the treatment of multiple sclerosis. Nature 502, 327-332.

Dhib-Jalbut, S., Marks, S., 2010. Interferon-beta mechanisms of action in multiple sclerosis. Neurology 74 (Suppl. 1), S17-S24.

Diab, A., Hussain, R.Z., Lovett-Racke, A.E., Chavis, J.A., Drew, P.D., Racke, M.K., 2004. Ligands for the peroxisome proliferator-activated receptor-gamma and the retinoid $\mathrm{X}$ receptor exert additive anti-inflammatory effects on experimental autoimmune encephalomyelitis. J. Neuroimmunol. 148, 116-126. 
Dutta, R., Trapp, B.D., 2011. Mechanisms of neuronal dysfunction and degeneration in multiple sclerosis. Prog. Neurobiol. 93, 1-12.

Dutta, R., McDonough, J., Yin, X., Peterson, J., Chang, A., Torres, T., Gudz, T., Macklin, W.B., Lewis, D.A., Fox, R.J., Rudick, R., Mirnics, K., Trapp, B.D., 2006. Mitochondrial dysfunction as a cause of axonal degeneration in multiple sclerosis patients. Ann. Neurol. 59, 478-489.

Dutta, R., McDonough, J., Chang, A., Swamy, L., Siu, A., Kidd, G.J., Rudick, R., Mirnics, K., Trapp, B.D., 2007. Activation of the ciliary neurotrophic factor (CNTF) signalling pathway in cortical neurons of multiple sclerosis patients. Brain 130, 2566-2576.

Dutta, R., Chang, A., Doud, M.K., Kidd, G.J., Ribaudo, M.V., Young, E.A., Fox, R.J., Staugaitis, S.M., Trapp, B.D., 2011. Demyelination causes synaptic alterations in hippocampi from multiple sclerosis patients. Ann. Neurol. 69, 445-454.

Ebers, G.C., 2004. Natural history of primary progressive multiple sclerosis. Mult. Scler. 10 (Suppl 1), S8-S13 (discussion S13-15).

Elliott, C., Lindner, M., Arthur, A., Brennan, K., Jarius, S., Hussey, J., Chan, A., Stroet, A Olsson, T., Willison, H., Barnett, S.C., Meinl, E., Linington, C., 2012. Functional identification of pathogenic autoantibody responses in patients with multiple sclerosis. Brain 135, 1819-1833.

Engelhardt, B., Ransohoff, R.M., 2012. Capture, crawl, cross: the T cell code to breach the blood-brain barriers. Trends Immunol. 33, 579-589.

Ermis, U., Weis, J., Schulz, J.B., 2013. PML in a patient treated with fumaric acid. N. Engl. J. Med. 368, 1657-1658.

Fagius, J., Lundgren, J., Oberg, G., 2009. Early highly aggressive MS successfully treated by hematopoietic stem cell transplantation. Mult. Scler. 15, 229-237.

Fazekas, F., Barkhof, F., Filippi, M., Grossman, R.I., Li, D.K., McDonald, W.I., McFarland, H.F., Paty, D.W., Simon, J.H., Wolinsky, J.S., Miller, D.H., 1999. The contribution of magnetic resonance imaging to the diagnosis of multiple sclerosis. Neurology 53, 448-456.

Ferguson, B., Matyszak, M.K., Esiri, M.M., Perry, V.H., 1997. Axonal damage in acute multiple sclerosis lesions. Brain 120 (Pt 3), 393-399.

Filippi, M., Rocca, M.A., 2012. The neurologist's dilemma: MS is a grey matter disease that standard clinical and MRI measures cannot assess adequately - no. Mult. Scler. 18, 557-558.

Filippi, M., Rocca, M.A., Barkhof, F., Bruck, W., Chen, J.T., Comi, G., DeLuca, G., De Stefano, N., Erickson, B.J., Evangelou, N., Fazekas, F., Geurts, J.J., Lucchinetti, C., Miller, D.H., Pelletier, D., Popescu, B.F., Lassmann, H., Attendees of the Correlation between Pathological MRI findings in MS workshop, 2012. Association between pathological and MRI findings in multiple sclerosis. Lancet Neurol. 11, 349-360.

Fischbach, M.A., Bluestone, J.A., Lim, W.A., 2013. Cell-based therapeutics: the next pillar of medicine. Sci. Transl. Med. 5,, 179ps177.

Fischer, M.T., Sharma, R., Lim, J.L., Haider, L., Frischer, J.M., Drexhage, J., Mahad, D., Bradl, M., van Horssen, J., Lassmann, H., 2012. NADPH oxidase expression in active multiple sclerosis lesions in relation to oxidative tissue damage and mitochondrial injury. Brain 135, 886-899.

Fischer, M.T., Wimmer, I., Hoftberger, R., Gerlach, S., Haider, L., Zrzavy, T., Hametner, S., Mahad, D., Binder, C.J., Krumbholz, M., Bauer, J., Bradl, M., Lassmann, H., 2013. Disease-specific molecular events in cortical multiple sclerosis lesions. Brain 136, 1799-1815.

Fong, C.Y., Gauthaman, K., Bongso, A., 2010. Teratomas from pluripotent stem cells: a clinical hurdle. J. Cell. Biochem. 111, 769-781.

Fox, R.J., Miller, D.H., Phillips, J.T., Hutchinson, M., Havrdova, E., Kita, M., Yang, M., Raghupathi, K., Novas, M., Sweetser, M.T., Viglietta, V., Dawson, K.T., Investigators, C.S., 2012a. Placebo-controlled phase 3 study of oral BG-12 or glatiramer in multiple sclerosis. N. Engl. J. Med. 367, 1087-1097.

Fox, R.J., Thompson, A., Baker, D., Baneke, P., Brown, D., Browne, P., Chandraratna, D., Ciccarelli, O., Coetzee, T., Comi, G., Feinstein, A., Kapoor, R., Lee, K., Salvetti, M., Sharrock, K., Toosy, A., Zaratin, P., Zuidwijk, K., 2012b. Setting a research agenda for progressive multiple sclerosis: the International Collaborative on Progressive MS. Mult. Scler. 18, 1534-1540.

Franklin, R.J., 2002. Why does remyelination fail in multiple sclerosis? Nat. Rev. Neurosci. 3, 705-714

Franklin, R.J., Gallo, V., 2014. The translational biology of remyelination: past, present, and future. Glia 62, 1905-1915.

Franklin, R.J., Gilson, J.M., Blakemore, W.F., 1997. Local recruitment of remyelinating cells in the repair of demyelination in the central nervous system. J. Neurosci. Res. 50, 337-344.

Friese, M.A., Fugger, L., 2007. T cells and microglia as drivers of multiple sclerosis pathology. Brain 130, 2755-2757.

Frischer, J.M., Bramow, S., Dal-Bianco, A., Lucchinetti, C.F., Rauschka, H., Schmidbauer, M., Laursen, H., Sorensen, P.S., Lassmann, H., 2009. The relation between inflammation and neurodegeneration in multiple sclerosis brains. Brain 132 1175-1189.

Fujinami, R.S., Oldstone, M.B., 1985. Amino acid homology between the encephalitogenic site of myelin basic protein and virus: mechanism for autoimmunity. Science 230, 1043-1045.

Galban-Horcajo, F., Halstead, S.K., McGonigal, R., Willison, H.J., 2014. The application of glycosphingolipid arrays to autoantibody detection in neuroimmunological disorders. Curr. Opin. Chem. Biol. 18, 78-86.

Genain, C.P., Cannella, B., Hauser, S.L., Raine, C.S., 1999. Identification of autoantibodies associated with myelin damage in multiple sclerosis. Nat. Med. 5, 170175.

Geurts, J.J., 2012. The neurologist's dilemma: MS is a grey matter disease that standard clinical and MRI measures cannot assess adequately - yes. Mult. Scler. $18,559-560$
Geurts, J.J., Wolswijk, G., Bo, L., van der Valk, P., Polman, C.H., Troost, D., Aronica, E. 2003. Altered expression patterns of group I and II metabotropic glutamate receptors in multiple sclerosis. Brain 126, 1755-1766.

Geurts, J.J., Bo, L., Roosendaal, S.D., Hazes, T., Daniels, R., Barkhof, F., Witter, M.P. Huitinga, I., van der Valk, P., 2007. Extensive hippocampal demyelination in multiple sclerosis. J. Neuropathol. Exp. Neurol. 66, 819-827.

Geurts, J.J., Stys, P.K., Minagar, A., Amor, S., Zivadinov, R., 2009. Gray matter pathology in (chronic) MS: modern views on an early observation. J. Neurol. Sci. 282, 12-20.

Gold, R., Kappos, L., Arnold, D.L., Bar-Or, A., Giovannoni, G., Selmaj, K., Tornatore, C. Sweetser, M.T., Yang, M., Sheikh, S.I., Dawson, K.T., Investigators, D.S., 2012 Placebo-controlled phase 3 study of oral BG-12 for relapsing multiple sclerosis. N. Engl. J. Med. 367, 1098-1107.

Goodin, D.S., Frohman, E.M., Hurwitz, B., O'Connor, P.W., Oger, J.J., Reder, A.T. Stevens, J.C., 2007. Neutralizing antibodies to interferon beta: assessment of their clinical and radiographic impact: an evidence report: report of the Therapeutics and Technology Assessment Subcommittee of the American Academy of Neurology. Neurology 68, 977-984.

Greter, M., Heppner, F.L., Lemos, M.P., Odermatt, B.M., Goebels, N., Laufer, T., Noelle R.J., Becher, B., 2005. Dendritic cells permit immune invasion of the CNS in an animal model of multiple sclerosis. Nat. Med. 11, 328-334

Hametner, S., Wimmer, I., Haider, L., Pfeifenbring, S., Bruck, W., Lassmann, H., 2013. Iron and neurodegeneration in the multiple sclerosis brain. Ann. Neurol. 74, 848-861

Harris, V.K., Faroqui, R., Vyshkina, T., Sadiq, S.A., 2012. Characterization of autologous mesenchymal stem cell-derived neural progenitors as a feasible source of stem cells for central nervous system applications in multiple sclerosis. Stem Cells Transl. Med. 1, 536-547.

Hartung, H.P., Gonsette, R., Konig, N., Kwiecinski, H., Guseo, A., Morrissey, S.P., Krapf, $H$. Zwingers, T., Mitoxantrone in Multiple Sclerosis Study, G, 2002. Mitoxantrone in progressive multiple sclerosis: a placebo-controlled, double-blind, randomised, multicentre trial. Lancet 360, 2018-2025.

Hauser, S.L., Oksenberg, J.R., 2006. The neurobiology of multiple sclerosis: genes, inflammation, and neurodegeneration. Neuron 52, 61-76.

Hauser, S.L., Waubant, E., Arnold, D.L., Vollmer, T., Antel, J., Fox, R.J., Bar-Or, A., Panzara, M., Sarkar, N., Agarwal, S., Langer-Gould, A., Smith, C.H., Group, H.T. 2008. B-cell depletion with rituximab in relapsing-remitting multiple sclerosis. N. Engl. J. Med. 358, 676-688.

Hawker, K., O'Connor, P., Freedman, M.S., Calabresi, P.A., Antel, J., Simon, J., Hauser S., Waubant, E., Vollmer, T., Panitch, H., Zhang, J., Chin, P., Smith, C.H., 2009. Rituximab in patients with primary progressive multiple sclerosis: results of a randomized double-blind placebo-controlled multicenter trial. Ann. Neurol. 66, 460-471, group, O.t.,

Hedstrom, A.K., Baarnhielm, M., Olsson, T., Alfredsson, L., 2009. Tobacco smoking, but not Swedish snuff use, increases the risk of multiple sclerosis. Neurology 73 , 696-701

Hedstrom, A.K., Baarnhielm, M., Olsson, T., Alfredsson, L., 2011. Exposure to environmental tobacco smoke is associated with increased risk for multiple sclerosis. Mult. Scler. 17, 788-793.

Heppner, F.L., Greter, M., Marino, D., Falsig, J., Raivich, G., Hovelmeyer, N., Waisman, A., Rulicke, T., Prinz, M., Priller, J., Becher, B., Aguzzi, A, 2005. Experimenta autoimmune encephalomyelitis repressed by microglial paralysis. Nat. Med. 11, $146-152$.

Hernan, M.A., Olek, M.J., Ascherio, A., 2001. Cigarette smoking and incidence of multiple sclerosis. Am. J. Epidemiol. 154, 69-74.

Hofman, F.M., Hinton, D.R., Johnson, K., Merrill, J.E., 1989. Tumor necrosis factor identified in multiple sclerosis brain. J. Exp. Med. 170, 607-612.

Howell, O.W., Reeves, C.A., Nicholas, R., Carassiti, D., Radotra, B., Gentleman, S.M., Serafini, B., Aloisi, F., Roncaroli, F., Magliozzi, R., Reynolds, R., 2011. Meningeal inflammation is widespread and linked to cortical pathology in multiple sclerosis. Brain 134, 2755-2771.

Huang, J.K., Franklin, R.J., 2012. Current status of myelin replacement therapies in multiple sclerosis. Prog. Brain Res. 201, 219-231.

Huang, J.K., Jarjour, A.A., Ffrench-Constant, C., Franklin, R.J.M., 2011a. Retinoid X receptors as a potential avenue for regenerative medicine in multiple sclerosis. Expert Rev. Neurother. 11, 467-468.

Huang, J.K., Jarjour, A.A., Nait Oumesmar, B., Kerninon, C., Williams, A., Krezel, W. Kagechika, H., Bauer, J., Zhao, C., Baron-Van Evercooren, A., Chambon, P. Ffrench-Constant, C., Franklin, R.J., 2011b. Retinoid X receptor gamma signaling accelerates CNS remyelination. Nat. Neurosci. 14, 45-53.

Neurology 45, 1277-1285

International Multiple Sclerosis Genetics, C., Wellcome Trust Case Control, C. Sawcer, S., Hellenthal, G., Pirinen, M., Spencer, C.C., Patsopoulos, N.A., Moutsianas, L., Dilthey, A., Su, Z., Freeman, C., Hunt, S.E., Edkins, S., Gray, E., Booth, D.R., Potter, S.C., Goris, A., Band, G., Oturai, A.B., Strange, A., Saarela, J., Bellenguez, C. Fontaine, B., Gillman, M., Hemmer, B., Gwilliam, R., Zipp, F., Jayakumar, A., Martin, R., Leslie, S., Hawkins, S., Giannoulatou, E., D’Alfonso, S., Blackburn, H., Martinelli Boneschi, F., Liddle, J., Harbo, H.F., Perez, M.L., Spurkland, A., Waller, M.J., Mycko, M.P., Ricketts, M., Comabella, M., Hammond, N., Kockum, I., McCann, O.T., Ban, M., Whittaker, P., Kemppinen, A., Weston, P., Hawkins, C. Widaa, S., Zajicek, J., Dronov, S., Robertson, N., Bumpstead, S.J., Barcellos, L.F. Ravindrarajah, R., Abraham, R., Alfredsson, L., Ardlie, K., Aubin, C., Baker, A., Baker, K., Baranzini, S.E., Bergamaschi, L., Bergamaschi, R., Bernstein, A Berthele, A., Boggild, M., Bradfield, J.P., Brassat, D., Broadley, S.A., Buck, D., Butzkueven, H., Capra, R., Carroll, W.M., Cavalla, P., Celius, E.G., Cepok, S. Chiavacci, R., Clerget-Darpoux, F., Clysters, K., Comi, G., Cossburn, M., 
Cournu-Rebeix, I., Cox, M.B., Cozen, W., Cree, B.A., Cross, A.H., Cusi, D., Daly, M.J., Davis, E., de Bakker, P.I., Debouverie, M., D'Hooghe, M.B., Dixon, K., Dobosi, R. Dubois, B., Ellinghaus, D., Elovaara, I., Esposito, F., Fontenille, C., Foote, S., Franke, A., Galimberti, D., Ghezzi, A., Glessner, J., Gomez, R., Gout, O., Graham, C., Grant S.F., Guerini, F.R., Hakonarson, H., Hall, P., Hamsten, A., Hartung, H.P., Heard, R.N., Heath, S., Hobart, J., Hoshi, M., Infante-Duarte, C., Ingram, G., Ingram, W., Islam, T., Jagodic, M., Kabesch, M., Kermode, A.G., Kilpatrick, T.J., Kim, C., Klopp, N., Koivisto, K., Larsson, M., Lathrop, M., Lechner-Scott, J.S., Leone, M.A., Leppa, V., Liljedahl, U., Bomfim, I.L., Lincoln, R.R., Link, J., Liu, J., Lorentzen, A.R., Lupoli, S., Macciardi, F., Mack, T., Marriott, M., Martinelli, V., Mason, D., McCauley, J.L., Mentch, F., Mero, I.L., Mihalova, T., Montalban, X., Mottershead, J., Myhr, K.M. Naldi, P., Ollier, W., Page, A., Palotie, A., Pelletier, J., Piccio, L., Pickersgill, T., Piehl, F., Pobywajlo, S., Quach, H.L., Ramsay, P.P., Reunanen, M., Reynolds, R., Rioux J.D., Rodegher, M., Roesner, S., Rubio, J.P., Ruckert, I.M., Salvetti, M., Salvi, E., Santaniello, A., Schaefer, C.A., Schreiber, S., Schulze, C., Scott, R.J., Sellebjerg, F., Selmaj, K.W., Sexton, D., Shen, L., Simms-Acuna, B., Skidmore, S., Sleiman, P.M., Smestad, C., Sorensen, P.S., Sondergaard, H.B., Stankovich, J., Strange, R.C., Sulonen, A.M., Sundqvist, E., Syvanen, A.C., Taddeo, F., Taylor, B., Blackwell, J.M., Tienari, P., Bramon, E., Tourbah, A., Brown, M.A., Tronczynska, E., Casas, J.P., Tubridy, N., Corvin, A., Vickery, J., Jankowski, J., Villoslada, P., Markus, H.S., Wang, K., Mathew, C.G., Wason, J., Palmer, C.N., Wichmann, H.E., Plomin, R., Willoughby, E., Rautanen, A., Winkelmann, J., Wittig, M., Trembath, R.C. Yaouanq, J., Viswanathan, A.C., Zhang, H., Wood, N.W., Zuvich, R., Deloukas, P., Langford, C., Duncanson, A., Oksenberg, J.R., Pericak-Vance, M.A., Haines, J.L., Olsson, T., Hillert, J., Ivinson, A.J., De Jager, P.L., Peltonen, L., Stewart, G.J., Hafler D.A., Hauser, S.L., McVean, G., Donnelly, P., Compston, A., 2011. Genetic risk and a primary role for cell-mediated immune mechanisms in multiple sclerosis. Nature 476, 214-219.

Investigators, C.T., Coles, A.J., Compston, D.A., Selmaj, K.W., Lake, S.L., Moran, S., Margolin, D.H., Norris, K., Tandon, P.K., 2008. Alemtuzumab vs. interferon beta1a in early multiple sclerosis. N. Engl. J. Med. 359, 1786-1801.

Irvine, K.A., Blakemore, W.F., 2008. Remyelination protects axons from demyelination-associated axon degeneration. Brain 131, 1464-1477.

Itoyama, Y., Webster, H.D., Sternberger, N.H., Richardson Jr., E.P., Walker, D.L., Quarles, R.H., Padgett, B.L., 1982. Distribution of papovavirus, myelin-associated glycoprotein, and myelin basic protein in progressive multifocal leukoencephalopathy lesions. Ann. Neurol. 11, 396-407.

Jacobs, L.D., Cookfair, D.L., Rudick, R.A., Herndon, R.M., Richert, J.R., Salazar, A.M., Fischer, J.S., Goodkin, D.E., Granger, C.V., Simon, J.H., Alam, J.J., Bartoszak, D.M., Bourdette, D.N., Braiman, J., Brownscheidle, C.M., Coats, M.E., Cohan, S.L., Dougherty, D.S., Kinkel, R.P., Mass, M.K., Munschauer 3rd, F.E., Priore, R.L. Pullicino, P.M., Scherokman, B.J., Whitham, R.H, et al., 1996. Intramuscular interferon beta-1a for disease progression in relapsing multiple sclerosis. The Multiple Sclerosis Collaborative Research Group (MSCRG). Ann. Neurol. 39, 285-294.

Jain, N., Bhatti, M.T., 2012. Fingolimod-associated macular edema: incidence, detection, and management. Neurology 78, 672-680.

JM, C., 1877. Lectures on the Diseases of the Nervous System, vol. 1. New Sydenham Society, London, , pp. 157-202.

Johnson, K.P., Brooks, B.R., Cohen, J.A., Ford, C.C., Goldstein, J., Lisak, R.P., Myers, L.W., Panitch, H.S., Rose, J.W., Schiffer, R.B., 1995. Copolymer 1 reduces relapse rate and improves disability in relapsing-remitting multiple sclerosis: results of a phase III multicenter, double-blind placebo-controlled trial. The Copolymer 1 Multiple Sclerosis Study Group. Neurology 45, 1268-1276.

Johnson, A.J., Mendez-Fernandez, Y., Moyer, A.M., Sloma, C.R., Pirko, I., Block, M.S., Rodriguez, M., Pease, L.R., 2005. Antigen-specific CD8+ T cells mediate a peptide-induced fatal syndrome. J. Immunol. 174, 6854-6862.

Johnson, A.J., Suidan, G.L., McDole, J., Pirko, I., 2007. The CD8 T cell in multiple sclerosis: suppressor cell or mediator of neuropathology? Int. Rev. Neurobiol. 79, 73-97.

Jones, J.L., Phuah, C.L., Cox, A.L., Thompson, S.A., Ban, M., Shawcross, J., Walton, A., Sawcer, S.J., Compston, A., Coles, A.J., 2009. IL-21 drives secondary autoimmunity in patients with multiple sclerosis, following therapeutic lymphocyte depletion with alemtuzumab (Campath-1H). J. Clin. Invest. 119, 2052-2061.

Kalkers, N.F., Barkhof, F., Bergers, E., van Schijndel, R., Polman, C.H., 2002. The effect of the neuroprotective agent riluzole on MRI parameters in primary progressive multiple sclerosis: a pilot study. Mult. Scler. 8, 532-533.

Kappos, L., Radue, E.W., O’Connor, P., Polman, C., Hohlfeld, R., Calabresi, P., Selmaj, K., Agoropoulou, C., Leyk, M., Zhang-Auberson, L., Burtin, P., Group, F.S., 2010. A placebo-controlled trial of oral fingolimod in relapsing multiple sclerosis. N. Engl. J. Med. 362, 387-401.

Karussis, D., Karageorgiou, C., Vaknin-Dembinsky, A., Gowda-Kurkalli, B., Gomori, J.M., Kassis, I., Bulte, J.W., Petrou, P., Ben-Hur, T., Abramsky, O., Slavin, S., 2010. Safety and immunological effects of mesenchymal stem cell transplantation in patients with multiple sclerosis and amyotrophic lateral sclerosis. Arch. Neurol. 67, 1187-1194.

Keegan, M., Konig, F., McClelland, R., Bruck, W., Morales, Y., Bitsch, A., Panitch, H. Lassmann, H., Weinshenker, B., Rodriguez, M., Parisi, J., Lucchinetti, C.F., 2005 Relation between humoral pathological changes in multiple sclerosis and response to therapeutic plasma exchange. Lancet 366, 579-582.

Khan, O., Rieckmann, P., Boyko, A., Selmaj, K., Zivadinov, R., Group, G.S., 2013. Three times weekly glatiramer acetate in relapsing-remitting multiple sclerosis. Ann. Neurol. 73, 705-713.

Kidd, D., Barkhof, F., McConnell, R., Algra, P.R., Allen, I.V., Revesz, T., 1999. Cortical lesions in multiple sclerosis. Brain 122 (Pt 1), 17-26.
Kieseier, B.C., 2011. The mechanism of action of interferon-beta in relapsing multiple sclerosis. CNS Drugs 25, 491-502.

Kim, H.M., Hwang, D.H., Choi, J.Y., Park, C.H., Suh-Kim, H., Kim, S.U., Kim, B.G., 2011. Differential and cooperative actions of Olig1 and Olig2 transcription factors on immature proliferating cells after contusive spinal cord injury. Glia 59, 1094-1106.

Kimiskidis, V., Sakellari, I., Tsimourtou, V., Kapina, V., Papagiannopoulos, S., Kazis, D., Vlaikidis, N., Anagnostopoulos, A., Fassas, A., 2008. Autologous stem-cell transplantation in malignant multiple sclerosis: a case with a favorable longterm outcome. Mult. Scler. 14, 278-283.

Klawiter, E.C., Piccio, L., Lyons, J.A., Mikesell, R., O’Connor, K.C., Cross, A.H., 2010. Elevated intrathecal myelin oligodendrocyte glycoprotein antibodies in multiple sclerosis. Arch. Neurol. 67, 1102-1108.

Kolasinski, J., Stagg, C.J., Chance, S.A., Deluca, G.C., Esiri, M.M., Chang, E.H., Palace, J.A., McNab, J.A., Jenkinson, M., Miller, K.L., Johansen-Berg, H., 2012. A combined post-mortem magnetic resonance imaging and quantitative histological study of multiple sclerosis pathology. Brain 135, 2938-2951.

Kornek, B., Lassmann, H., 1999. Axonal pathology in multiple sclerosis. A historical note. Brain Pathol. 9, 651-656.

Krumbholz, M., Derfuss, T., Hohlfeld, R., Meinl, E., 2012. B cells and antibodies in multiple sclerosis pathogenesis and therapy. Nat. Rev. Neurol. 8, 613-623.

Kuhlmann, T., Miron, V., Cui, Q., Wegner, C., Antel, J., Bruck, W., 2008. Differentiation block of oligodendroglial progenitor cells as a cause for remyelination failure in chronic multiple sclerosis. Brain 131, 1749-1758.

Kutzelnigg, A., Lucchinetti, C.F., Stadelmann, C., Bruck, W., Rauschka, H., Bergmann, M., Schmidbauer, M., Parisi, J.E., Lassmann, H., 2005. Cortical demyelination and diffuse white matter injury in multiple sclerosis. Brain 128, 2705-2712.

Kutzelnigg, A., Faber-Rod, J.C., Bauer, J., Lucchinetti, C.F., Sorensen, P.S., Laursen, H., Stadelmann, C., Bruck, W., Rauschka, H., Schmidbauer, M., Lassmann, H., 2007. Widespread demyelination in the cerebellar cortex in multiple sclerosis. Brain Pathol. 17, 38-44.

Lampasona, V., Franciotta, D., Furlan, R., Zanaboni, S., Fazio, R., Bonifacio, E., Comi, G., Martino, G., 2004. Similar low frequency of anti-MOG IgG and IgM in MS patients and healthy subjects. Neurology 62, 2092-2094.

Lang, H.L., Jacobsen, H., Ikemizu, S., Andersson, C., Harlos, K., Madsen, L., Hjorth, P., Sondergaard, L., Svejgaard, A., Wucherpfennig, K., Stuart, D.I., Bell, J.I., Jones, E.Y., Fugger, L., 2002. A functional and structural basis for TCR cross-reactivity in multiple sclerosis. Nat. Immunol. 3, 940-943.

Langer-Gould, A., Atlas, S.W., Green, A.J., Bollen, A.W., Pelletier, D., 2005. Progressive multifocal leukoencephalopathy in a patient treated with natalizumab. N. Engl. J. Med. 353, 375-381.

Lassmann, H., 2003. Hypoxia-like tissue injury as a component of multiple sclerosis lesions. J. Neurol. Sci. 206, 187-191.

Lassmann, H., 2011. Review: the architecture of inflammatory demyelinating lesions: implications for studies on pathogenesis. Neuropathol. Appl. Neurobiol. 37, 698-710.

Lassmann, H., 2012. Cortical lesions in multiple sclerosis: inflammation versus neurodegeneration. Brain 135, 2904-2905.

Lassmann, H., 2013. Multiple sclerosis: Lessons from molecular neuropathology. Exp. Neurol. 262, 2-7.

Lassmann, H., van Horssen, J., Mahad, D., 2012. Progressive multiple sclerosis: pathology and pathogenesis. Nat. Rev. Neurol. 8, 647-656.

Leary, S.M., Miller, D.H., Stevenson, V.L., Brex, P.A., Chard, D.T., Thompson, A.J., 2003. Interferon beta-1a in primary progressive MS: an exploratory, randomized, controlled trial. Neurology 60, 44-51.

Levin, L.I., Munger, K.L., O’Reilly, E.J., Falk, K.I., Ascherio, A., 2010. Primary infection with the Epstein-Barr virus and risk of multiple sclerosis. Ann. Neurol. 67, 824-830.

Liang, G., Zhang, Y., 2013. Genetic and epigenetic variations in iPSCs: potential causes and implications for application. Cell Stem Cell 13, 149-159.

Libbey, J.E., McCoy, L.L., Fujinami, R.S., 2007. Molecular mimicry in multiple sclerosis. Int. Rev. Neurobiol. 79, 127-147.

Link, H., Huang, Y.M., 2006. Oligoclonal bands in multiple sclerosis cerebrospinal fluid: an update on methodology and clinical usefulness. J. Neuroimmunol. 180, 17-28.

Loma, I., Heyman, R., 2011. Multiple sclerosis: pathogenesis and treatment. Curr. Neuropharmacol. 9, 409-416.

Longoni, G., Rocca, M.A., Pagani, E., Riccitelli, G.C., Colombo, B., Rodegher, M., Falini, A., Comi, G., Filippi, M., 2013. Deficits in memory and visuospatial learning correlate with regional hippocampal atrophy in MS. Brain Struct. Funct. 220, 435-444.

Lublin, F.D., Reingold, S.C. 1996. Defining the clinical course of multiple sclerosis: results of an international survey, National Multiple Sclerosis Society (USA) Advisory Committee on Clinical Trials of New Agents in Multiple Sclerosis. Neurology 46, 907-911.

Lublin, F.D., Reingold, S.C., Cohen, J.A., Cutter, G.R., Sorensen, P.S., Thompson, A.J., Wolinsky, J.S., Balcer, L.J., Banwell, B., Barkhof, F., Bebo Jr., B., Calabresi, P.A., Clanet, M., Comi, G., Fox, R.J., Freedman, M.S., Goodman, A.D., Inglese, M., Kappos, L., Kieseier, B.C., Lincoln, J.A., Lubetzki, C., Miller, A.E., Montalban, X. O’Connor, P.W., Petkau, J., Pozzilli, C., Rudick, R.A., Sormani, M.P., Stuve, O., Waubant, E., Polman, C.H., 2014. Defining the clinical course of multiple sclerosis: the 2013 revisions. Neurology 83, 278-286.

Lucchinetti, C., Bruck, W., Parisi, J., Scheithauer, B., Rodriguez, M., Lassmann, H., 1999. A quantitative analysis of oligodendrocytes in multiple sclerosis lesions. A study of 113 cases. Brain 122 (Pt 12), 2279-2295 
Lucchinetti, C., Bruck, W., Parisi, J., Scheithauer, B., Rodriguez, M., Lassmann, H., 2000. Heterogeneity of multiple sclerosis lesions: implications for the pathogenesis of demyelination. Ann. Neurol. 47, 707-717.

Lucchinetti, C.F., Popescu, B.F., Bunyan, R.F., Moll, N.M., Roemer, S.F., Lassmann, H., Bruck, W., Parisi, J.E., Scheithauer, B.W., Giannini, C., Weigand, S.D., Mandrekar, J., Ransohoff, R.M., 2011. Inflammatory cortical demyelination in early multiple sclerosis. N. Engl. J. Med. 365, 2188-2197.

Ludwin, S.K., Johnson, E.S., 1981. Evidence for a "dying-back" gliopathy in demyelinating disease. Ann. Neurol. 9, 301-305.

Ludwin, S.K., Maitland, M., 1984. Long-term remyelination fails to reconstitute normal thickness of central myelin sheaths. J. Neurol. Sci. 64, 193-198.

Lutterotti, A., Martin, R., 2008. Getting specific: monoclonal antibodies in multiple sclerosis. Lancet Neurol. 7, 538-547.

Lycklama, G., Thompson, A., Filippi, M., Miller, D., Polman, C., Fazekas, F., Barkhof, F., 2003. Spinal-cord MRI in multiple sclerosis. Lancet Neurol. 2, 555-562.

Magliozzi, R., Howell, O., Vora, A., Serafini, B., Nicholas, R., Puopolo, M., Reynolds, R. Aloisi, F., 2007. Meningeal B-cell follicles in secondary progressive multiple sclerosis associate with early onset of disease and severe cortical pathology. Brain 130, 1089-1104.

Mahad, D.J., Trebst, C., Kivisakk, P., Staugaitis, S.M., Tucky, B., Wei, T., Lucchinetti, C.F., Lassmann, H., Ransohoff, R.M., 2004. Expression of chemokine receptors CCR1 and CCR5 reflects differential activation of mononuclear phagocytes in pattern II and pattern III multiple sclerosis lesions. J. Neuropathol. Exp. Neurol. 63, 262-273.

Mahad, D., Ziabreva, I., Lassmann, H., Turnbull, D., 2008. Mitochondrial defects in acute multiple sclerosis lesions. Brain 131, 1722-1735.

Mancardi, G.L., Murialdo, A., Rossi, P., Gualandi, F., Martino, G., Marmont, A., Ciceri, F., Schenone, A., Parodi, R.C., Capello, E., Comi, G., Uccelli, A., 2005. Autologous stem cell transplantation as rescue therapy in malignant forms of multiple sclerosis. Mult. Scler. 11, 367-371.

Mangas, A., Covenas, R., Geffard, M., 2010. New drug therapies for multiple sclerosis. Curr. Opin. Neurol. 23, 287-292.

Marriott, J.J., Miyasaki, J.M., Gronseth, G., O’Connor, P.W., Therapeutics, Technology Assessment Subcommittee of the American Academy of, N., 2010. Evidence Report: the efficacy and safety of mitoxantrone (Novantrone) in the treatment of multiple sclerosis: report of the Therapeutics and Technology Assessment Subcommittee of the American Academy of Neurology. Neurology 74, 1463-1470.

Martinelli Boneschi, F., Rovaris, M., Capra, R., Comi, G., 2005. Mitoxantrone for multiple sclerosis. Cochrane Database Syst. Rev. CD002127.

Martinelli, V., Cocco, E., Capra, R., Salemi, G., Gallo, P., Capobianco, M., Pesci, I., Ghezzi, A., Pozzilli, C., Lugaresi, A., Bellantonio, P., Amato, M.P., Grimaldi, L.M. Trojano, M., Mancardi, G.L., Bergamaschi, R., Gasperini, C., Rodegher, M., Straffi, L., Ponzio, M., Comi, G., Italian Mitoxantrone, G., 2011. Acute myeloid leukemia in Italian patients with multiple sclerosis treated with mitoxantrone. Neurology 77, 1887-1895.

Martinelli, V., Dalla Costa, G., Colombo, B., Dalla Libera, D., Rubinacci, A., Filippi, M., Furlan, R., Comi, G., 2014. Vitamin D levels and risk of multiple sclerosis in patients with clinically isolated syndromes. Mult. Scler. 20, 147-155.

Martino, G., 2004. How the brain repairs itself: new therapeutic strategies in inflammatory and degenerative CNS disorders. Lancet Neurol. 3, 372-378.

Martino, G., Bacigaluppi, M., Peruzzotti-Jametti, L., 2011. Therapeutic stem cell plasticity orchestrates tissue plasticity. Brain 134, 1585-1587.

Massaro, A.R., Soranzo, C., Carnevale, A., 1997. Cerebrospinal-fluid ciliary neurotrophic factor in neurological patients. Eur. Neurol. 37, 243-246.

Matute, C., Alberdi, E., Domercq, M., Perez-Cerda, F., Perez-Samartin, A., SanchezGomez, M.V., 2001. The link between excitotoxic oligodendroglial death and demyelinating diseases. Trends Neurosci. 24, 224-230.

Mayo, L., Quintana, F.J., Weiner, H.L., 2012. The innate immune system in demyelinating disease. Immunol. Rev. 248, 170-187.

McCarthy, D.P., Richards, M.H., Miller, S.D., 2012. Mouse models of multiple sclerosis: experimental autoimmune encephalomyelitis and Theiler's virusinduced demyelinating disease. Methods Mol. Biol. 900, 381-401.

McMahon, E.J., Bailey, S.L., Castenada, C.V., Waldner, H., Miller, S.D., 2005. Epitope spreading initiates in the CNS in two mouse models of multiple sclerosis. Nat. Med. 11, 335-339.

Metz, I., Weigand, S.D., Popescu, B.F., Frischer, J.M., Parisi, J.E., Guo, Y., Lassmann, H., Bruck, W., Lucchinetti, C.F., 2014. Pathologic heterogeneity persists in early active multiple sclerosis lesions. Ann. Neurol. 75, 728-738.

Mi, S., Pepinsky, R.B., Cadavid, D., 2013. Blocking LINGO-1 as a therapy to promote CNS repair: from concept to the clinic. CNS Drugs 27, 493-503.

Miller, D., Barkhof, F., Montalban, X., Thompson, A., Filippi, M., 2005a. Clinically isolated syndromes suggestive of multiple sclerosis, Part 2: Non-conventional MRI, recovery processes, and management. Lancet Neurol. 4, 341-348.

Miller, D., Barkhof, F., Montalban, X., Thompson, A., Filippi, M., 2005b. Clinically isolated syndromes suggestive of multiple sclerosis, Part I: Natural history, pathogenesis, diagnosis, and prognosis. Lancet Neurol. 4, 281-288.

Minagar, A., Alexander, J.S., 2003. Blood-brain barrier disruption in multiple sclerosis. Mult. Scler. 9, 540-549.

Miron, V.E., Franklin, R.J., 2014. Macrophages and CNS remyelination. J. Neurochem. 130, 165-171.

Mohyeddin Bonab, M., Yazdanbakhsh, S., Lotfi, J., Alimoghaddom, K., Talebian, F., Hooshmand, F., Ghavamzadeh, A., Nikbin, B., 2007. Does mesenchymal stem cell therapy help multiple sclerosis patients? Report of a pilot study. Iran. J. Immunol. 4, 50-57.

Moll, N.M., Hong, E., Fauveau, M., Naruse, M., Kerninon, C., Tepavcevic, V., Klopstein, A., Seilhean, D., Chew, L.J., Gallo, V., Nait Oumesmar, B., 2013. SOX17 is expressed in regenerating oligodendrocytes in experimental models of demyelination and in multiple sclerosis. Glia 61, 1659-1672.

Montalban, X., Tintore, M., Swanton, J., Barkhof, F., Fazekas, F., Filippi, M., Frederiksen, J., Kappos, L., Palace, J., Polman, C., Rovaris, M., de Stefano, N., Thompson, A., Yousry, T., Rovira, A., Miller, D.H., 2010. MRI criteria for MS in patients with clinically isolated syndromes. Neurology 74, 427-434.

Munger, K.L., Zhang, S.M., O'Reilly, E., Hernan, M.A., Olek, M.J., Willett, W.C. Ascherio, A., 2004. Vitamin D intake and incidence of multiple sclerosis. Neurology 62, 60-65.

Munger, K.L., Levin, L.I., O’Reilly, E.J., Falk, K.I., Ascherio, A., 2011. Anti-Epstein-Barr virus antibodies as serological markers of multiple sclerosis: a prospective study among United States military personnel. Mult. Scler. 17, 1185-1193.

Munz, C., Lunemann, J.D., Getts, M.T., Miller, S.D., 2009. Antiviral immune responses: triggers of or triggered by autoimmunity? Nat. Rev. Immunol. 9, 246-258.

Munzel, E.J., Williams, A., 2013. Promoting remyelination in multiple sclerosisrecent advances. Drugs 73, 2017-2029.

Murphy, M.P., 2009. How mitochondria produce reactive oxygen species. Biochem. J. $417,1-13$

Murphy, K.M., Reiner, S.L., 2002. The lineage decisions of helper T cells. Nat. Rey. Immunol. 2, 933-944.

Murtie, J.C., Zhou, Y.X., Le, T.Q., Vana, A.C., Armstrong, R.C., 2005. PDGF and FGF2 pathways regulate distinct oligodendrocyte lineage responses in experimental demyelination with spontaneous remyelination. Neurobiol. Dis. 19, 171-182.

Nakatani, H., Martin, E., Hassani, H., Clavairoly, A., Maire, C.L., Viadieu, A., Kerninon, C., Delmasure, A., Frah, M., Weber, M., Nakafuku, M., Zalc, B., Thomas, J.L., Guillemot, F., Nait-Oumesmar, B., Parras, C., 2013. Ascl1/Mash1 promotes brain oligodendrogenesis during myelination and remyelination. J. Neurosci. 33, 9752-9768.

Nave, K.A., 2010. Myelination and the trophic support of long axons. Nat. Rev. Neurosci. 11, 275-283.

Nave, K.A., Trapp, B.D., 2008. Axon-glial signaling and the glial support of axon function. Annu. Rev. Neurosci. 31, 535-561.

Niehaus, A., Shi, J., Grzenkowski, M., Diers-Fenger, M., Archelos, J., Hartung, H.P. Toyka, K., Bruck, W., Trotter, J., 2000. Patients with active relapsing-remitting multiple sclerosis synthesize antibodies recognizing oligodendrocyte progenitor cell surface protein: implications for remyelination. Ann. Neurol. 48, 362371.

Nijeholt, G.J., van Walderveen, M.A., Castelijns, J.A., van Waesberghe, J.H., Polman, C., Scheltens, P., Rosier, P.F., Jongen, P.J., Barkhof, F., 1998. Brain and spinal cord abnormalities in multiple sclerosis. Correlation between MRI parameters, clinical subtypes and symptoms. Brain 121 (Pt 4), 687-697.

Nissen, K.K., Laska, M.J., Hansen, B., Terkelsen, T., Villesen, P., Bahrami, S., Petersen, T., Pedersen, F.S., Nexo, B.A., 2013. Endogenous retroviruses and multiple sclerosis-new pieces to the puzzle. BMC Neurol. 13, 111.

O'Connor, P., Wolinsky, J.S., Confavreux, C., Comi, G., Kappos, L., Olsson, T.P., Benzerdjeb, H., Truffinet, P., Wang, L., Miller, A., Freedman, M.S., Group, T.T., 2011. Randomized trial of oral teriflunomide for relapsing multiple sclerosis. N. Engl. J. Med. 365, 1293-1303.

Owens, G.P., Bennett, J.L., Gilden, D.H., Burgoon, M.P., 2006. The B cell response in multiple sclerosis. Neurol. Res. 28, 236-244.

Owens, G.P., Gilden, D., Burgoon, M.P., Yu, X., Bennett, J.L., 2011. Viruses and multiple sclerosis. Neuroscientist 17, 659-676.

Patrikios, P., Stadelmann, C., Kutzelnigg, A., Rauschka, H., Schmidbauer, M., Laursen, H., Sorensen, P.S., Bruck, W., Lucchinetti, C., Lassmann, H., 2006. Remyelination is extensive in a subset of multiple sclerosis patients. Brain 129, 3165-3172.

Paty, D.W., Li, D.K., 1993. Interferon beta-1b is effective in relapsing-remitting multiple sclerosis. II. MRI analysis results of a multicenter, randomized, doubleblind, placebo-controlled trial. UBC MS/MRI Study Group and the IFNB Multiple Sclerosis Study Group. Neurology 43, 662-667.

Pearl, J.I., Kean, L.S., Davis, M.M., Wu, J.C., 2012. Pluripotent stem cells: immune to the immune system? Sci. Transl. Med. 4, 164ps125.

Peferoen, L.A., Lamers, F., Lodder, L.N., Gerritsen, W.H., Huitinga, I., Melief, J., Giovannoni, G., Meier, U., Hintzen, R.Q., Verjans, G.M., van Nierop, G.P., Vos, W., Peferoen-Baert, R.M., Middeldorp, J.M., van der Valk, P., Amor, S., 2010 Epstein Barr virus is not a characteristic feature in the central nervous system in established multiple sclerosis. Brain 133, e137.

Penna, G., Roncari, A., Amuchastegui, S., Daniel, K.C., Berti, E., Colonna, M., Adorini, L., 2005. Expression of the inhibitory receptor ILT3 on dendritic cells is dispensable for induction of CD4+Foxp3+ regulatory $\mathrm{T}$ cells by 1,25 -dihydroxyvitamin D3. Blood 106, 3490-3497.

Perry, V.H., Nicoll, J.A., Holmes, C., 2010. Microglia in neurodegenerative disease. Nat. Rev. Neurol. 6, 193-201.

Peruzzotti-Jametti, L., Donega, M., Giusto, E., Mallucci, G., Marchetti, B., Pluchino, S., 2014. The role of the immune system in central nervous system plasticity after acute injury. Neuroscience 26, 210-221.

Peterson, J.W., Bo, L., Mork, S., Chang, A., Trapp, B.D., 2001. Transected neurites, apoptotic neurons, and reduced inflammation in cortical multiple sclerosis lesions. Ann. Neurol. 50, 389-400.

Petry, K.G., Boullerne, A.I., Pousset, F., Brochet, B., Caille, J.M., Dousset, V., 2000 Experimental allergic encephalomyelitis animal models for analyzing features of multiple sclerosis. Pathol.-Biol. 48, 47-53.

Piccio, L., Buonsanti, C., Mariani, M., Cella, M., Gilfillan, S., Cross, A.H., Colonna, M. Panina-Bordignon, P., 2007. Blockade of TREM-2 exacerbates experimental autoimmune encephalomyelitis. Eur. J. Immunol. 37, 1290-1301.

Lancet 352, 1491-1497. 
Pluchino, S., Cossetti, C., 2013. How stem cells speak with host immune cells in inflammatory brain diseases. Glia 61, 1379-1401.

Pluchino, S., Zanotti, L., Rossi, B., Brambilla, E., Ottoboni, L., Salani, G., Martinello, M., Cattalini, A., Bergami, A., Furlan, R., Comi, G., Constantin, G., Martino, G., 2005. Neurosphere-derived multipotent precursors promote neuroprotection by an immunomodulatory mechanism. Nature 436, 266-271.

Pluchino, S., Gritti, A., Blezer, E., Amadio, S., Brambilla, E., Borsellino, G., Cossetti, C., Del Carro, U., Comi, G., t Hart, B., Vescovi, A., Martino, G., 2009. Human neura stem cells ameliorate autoimmune encephalomyelitis in non-human primates. Ann. Neurol. 66, 343-354.

Politis, M., Giannetti, P., Su, P., Turkheimer, F., Keihaninejad, S., Wu, K., Waldman, A. Malik, O., Matthews, P.M., Reynolds, R., Nicholas, R., Piccini, P., 2012. Increased PK11195 PET binding in the cortex of patients with MS correlates with disability. Neurology 79, 523-530.

Polman, C.H., O'Connor, P.W., Havrdova, E., Hutchinson, M., Kappos, L., Miller, D.H. Phillips, J.T., Lublin, F.D., Giovannoni, G., Wajgt, A., Toal, M., Lynn, F., Panzara, M.A., Sandrock, A.W., 2006a. A randomized, placebo-controlled trial of natalizumab for relapsing multiple sclerosis. N. Engl. J. Med. 354, 899-910.

Polman, C.H., O'Connor, P.W., Havrdova, E., Hutchinson, M., Kappos, L., Miller, D.H. Phillips, J.T., Lublin, F.D., Giovannoni, G., Wajgt, A., Toal, M., Lynn, F., Panzara, M.A., Sandrock, A.W., Investigators, A., 2006b. A randomized, placebo-controlled trial of natalizumab for relapsing multiple sclerosis. N. Engl. J. Med. 354, 899-910.

Polman, C.H., Reingold, S.C., Banwell, B., Clanet, M., Cohen, J.A., Filippi, M., Fujihara, K., Havrdova, E., Hutchinson, M., Kappos, L., Lublin, F.D., Montalban, X., O'Connor, P., Sandberg-Wollheim, M., Thompson, A.J., Waubant, E., Weinshenker, B. Wolinsky, J.S., 2011. Diagnostic criteria for multiple sclerosis: 2010 revisions to the McDonald criteria. Ann. Neurol. 69, 292-302.

Popescu, B.F., Lucchinetti, C.F., 2012. Meningeal and cortical grey matter pathology in multiple sclerosis. BMC Neurol. 12, 11

Popescu, B.F., Bunyan, R.F., Parisi, J.E., Ransohoff, R.M., Lucchinetti, C.F., 2011. A case of multiple sclerosis presenting with inflammatory cortical demyelination. Neurology 76, 1705-1710.

Presslauer, S., Milosavljevic, D., Brucke, T., Bayer, P., Hubl, W., 2008. Elevated levels of kappa free light chains in CSF support the diagnosis of multiple sclerosis. J. Neurol. 255, 1508-1514.

Prineas, J.W., Kwon, E.E., Cho, E.S., Sharer, L.R., Barnett, M.H., Oleszak, E.L., Hoffman, B., Morgan, B.P., 2001. Immunopathology of secondary-progressive multiple sclerosis. Ann. Neurol. 50, 646-657.

Racke, M.K., Lovett-Racke, A.E., Karandikar, N.J., 2010. The mechanism of action of glatiramer acetate treatment in multiple sclerosis. Neurology 74 (Suppl. 1) S25-S30.

Radue, E.W., Stuart, W.H., Calabresi, P.A., Confavreux, C., Galetta, S.L., Rudick, R.A., Lublin, F.D., Weinstock-Guttman, B., Wynn, D.R., Fisher, E., Papadopoulou, A. Lynn, F., Panzara, M.A., Sandrock, A.W., Investigators, S., 2010. Natalizumab plus interferon beta-1a reduces lesion formation in relapsing multiple sclerosis. J Neurol. Sci. 292, 28-35.

Ramos-Zuniga, R., Gonzalez-Perez, O., Macias-Ornelas, A., Capilla-Gonzalez, V. Quinones-Hinojosa, A., 2012. Ethical implications in the use of embryonic and adult neural stem cells. Stem Cells Int. 2012, 470949.

Ramo-Tello, C., Grau-Lopez, L., Tintore, M., Rovira, A., Ramio i Torrenta, L., Brieva, L Cano, A., Carmona, O., Saiz, A., Torres, F., Giner, P., Nos, C., Massuet, A. Montalban, X., Martinez-Caceres, E., Costa, J., 2014. A randomized clinical trial of oral versus intravenous methylprednisolone for relapse of MS. Mult. Scler. 20, $717-725$.

Lancet 352, 1498-1504

Rawji, K.S., Yong, V.W., 2013. The benefits and detriments of macrophages/microglia in models of multiple sclerosis. Clin. Dev. Immunol. 2013, 948976.

Reindl, M., Linington, C., Brehm, U., Egg, R., Dilitz, E., Deisenhammer, F., Poewe, W., Berger, T., 1999. Antibodies against the myelin oligodendrocyte glycoprotein and the myelin basic protein in multiple sclerosis and other neurological diseases: a comparative study. Brain 122 (Pt 11), 2047-2056.

Rieckmann, P., 2009. Concepts of induction and escalation therapy in multiple sclerosis. J. Neurol. Sci. 277 (Suppl 1), S42-S45.

Rinaldi, S., Brennan, K.M., Willison, H.J., 2012. Combinatorial glycoarray. Methods Mol. Biol. 808, 413-423.

Rocca, M.A., Colombo, B., Falini, A., Ghezzi, A., Martinelli, V., Scotti, G., Comi, G., Filippi, M., 2005. Cortical adaptation in patients with MS: a cross-sectional functional MRI study of disease phenotypes. Lancet Neurol. 4, 618-626.

Rodgers, J.M., Robinson, A.P., Miller, S.D., 2013. Strategies for protecting oligodendrocytes and enhancing remyelination in multiple sclerosis. Discov. Med. 86 $53-63$.

Rosland, G.V., Svendsen, A., Torsvik, A., Sobala, E., McCormack, E., Immervoll, H., Mysliwietz, J., Tonn, J.C., Goldbrunner, R., Lonning, P.E., Bjerkvig, R., Schichor, C., 2009. Long-term cultures of bone marrow-derived human mesenchymal stem cells frequently undergo spontaneous malignant transformation. Cancer Res. 69, 5331-5339.

Sakaguchi, S., Ono, M., Setoguchi, R., Yagi, H., Hori, S., Fehervari, Z., Shimizu, J., Takahashi, T., Nomura, T., 2006. Foxp3+CD25+CD4+ natural regulatory T cells in dominant self-tolerance and autoimmune disease. Immunol. Rev. 212, 8-27.

Sanders, P., De Keyser, J., 2007. Janus faces of microglia in multiple sclerosis. Brain Res. Rev. 54, 274-285.

Sargsyan, S.A., Shearer, A.J., Ritchie, A.M., Burgoon, M.P., Anderson, S., Hemmer, B., Stadelmann, C., Gattenlohner, S., Owens, G.P., Gilden, D., Bennett, J.L., 2010. Absence of Epstein-Barr virus in the brain and CSF of patients with multiple sclerosis. Neurology 74, 1127-1135.
Scalfari, A., Neuhaus, A., Daumer, M., Muraro, P.A., Ebers, G.C., 2014. Onset of secondary progressive phase and long-term evolution of multiple sclerosis. J. Neurol. Neurosurg. Psychiatry 85, 67-75.

Scannevin, R.H., Chollate, S., Jung, M.Y., Shackett, M., Patel, H., Bista, P., Zeng, W., Ryan, S., Yamamoto, M., Lukashev, M., Rhodes, K.J., 2012. Fumarates promote cytoprotection of central nervous system cells against oxidative stress via the nuclear factor (erythroid-derived 2)-like 2 pathway. J. Pharmacol. Exp. Therap. $341,274-284$.

Schwab, S.R., Cyster, J.G., 2007. Finding a way out: lymphocyte egress from lymphoid organs. Nat. Immunol. 8, 1295-1301.

Scotton, C., Milliken, D., Wilson, J., Raju, S., Balkwill, F., 2001. Analysis of CC chemokine and chemokine receptor expression in solid ovarian tumours. Br. J. Cancer 85, 891-897.

Selmaj, K., Raine, C.S., Cannella, B., Brosnan, C.F., 1991. Identification of lymphotoxin and tumor necrosis factor in multiple sclerosis lesions. J. Clin. Invest. 87, 949954.

Serafini, B., Rosicarelli, B., Franciotta, D., Magliozzi, R., Reynolds, R., Cinque, P., Andreoni, L., Trivedi, P., Salvetti, M., Faggioni, A., Aloisi, F., 2007. Dysregulated Epstein-Barr virus infection in the multiple sclerosis brain. J. Exp. Med. 204, 2899-2912.

Shevchenko, J.L., Kuznetsov, A.N., Ionova, T.I., Melnichenko, V.Y., Fedorenko, D.A., Kartashov, A.V., Kurbatova, K.A., Gorodokin, G.I., Novik, A.A., 2012. Autologous hematopoietic stem cell transplantation with reduced-intensity conditioning in multiple sclerosis. Exp. Hematol. 40, 892-898.

Sixt, M., Engelhardt, B., Pausch, F., Hallmann, R., Wendler, O., Sorokin, L.M., 2001. Endothelial cell laminin isoforms, laminins 8 and 10, play decisive roles in T cell recruitment across the blood-brain barrier in experimental autoimmune encephalomyelitis. J. Cell Biol. 153, 933-946.

Sloka, J.S., Stefanelli, M., 2005. The mechanism of action of methylprednisolone in the treatment of multiple sclerosis. Mult. Scler. 11, 425-432.

Smith, K.J., 2007. Sodium channels and multiple sclerosis: roles in symptom production, damage and therapy. Brain Pathol. 17, 230-242.

Smith, K.J., Blakemore, W.F., McDonald, W.I., 1979. Central remyelination restores secure conduction. Nature 280, 395-396.

Sohn, J., Natale, J., Chew, L.J., Belachew, S., Cheng, Y., Aguirre, A., Lytle, J., NaitOumesmar, B., Kerninon, C., Kanai-Azuma, M., Kanai, Y., Gallo, V., 2006. Identification of Sox17 as a transcription factor that regulates oligodendrocyte development. J. Neurosci. 26, 9722-9735.

Sospedra, M., Martin, R., 2005. Immunology of multiple sclerosis. Annu. Rev. Immunol. 23, 683-747.

Steinman, L., 1995. Multiple sclerosis. Presenting an odd autoantigen. Nature 375 739-740.

Stern, J.N., Yaari, G., Vander Heiden, J.A., Church, G., Donahue, W.F., Hintzen, R.Q., Huttner, A.J., Laman, J.D. Nagra, R.M. Nylander, A., Pitt, D., Ramanan, S. Siddiqui, B.A., Vigneault, F., Kleinstein, S.H., Hafler, D.A., O'Connor, K.C., 2014. B cells populating the multiple sclerosis brain mature in the draining cervical lymph nodes. Sci. Transl. Med. 6, 248ra107.

Stoffels, J.M., de Jonge, J.C., Stancic, M., Nomden, A., van Strien, M.E., Ma, D., Siskova, Z., Maier, O., Ffrench-Constant, C., Franklin, R.J., Hoekstra, D., Zhao, C., Baron, W., 2013. Fibronectin aggregation in multiple sclerosis lesions impairs remyelination. Brain 136, 116-131.

Sundstrom, P., Nystrom, L., Hallmans, G., 2008. Smoke exposure increases the risk for multiple sclerosis. Eur. J. Neurol. 15, 579-583.

Sung, W.S., Chen, Y.Y., Dubey, A., Hunn, A., 2008. Spontaneous regression of syringomyelia - review of the current aetiological theories and implications for surgery. J. Clin. Neurosci. 15, 1185-1188.

Takahashi, K., Prinz, M., Stagi, M., Chechneva, O., Neumann, H., 2007. TREM2transduced myeloid precursors mediate nervous tissue debris clearance and facilitate recovery in an animal model of multiple sclerosis. PLoS Med. 4, e124.

Tepavcevic, V., Kerninon, C., Aigrot, M.S., Meppiel, E., Mozafari, S., Arnould-Laurent, R., Ravassard, P., Kennedy, T.E., Nait-Oumesmar, B., Lubetzki, C., 2014. Early netrin-1 expression impairs central nervous system remyelination. Ann. Neurol. 76, 252-268.

Thier, M., Worsdorfer, P., Lakes, Y.B., Gorris, R., Herms, S., Opitz, T., Seiferling, D., Quandel, T., Hoffmann, P., Nothen, M.M., Brustle, O., Edenhofer, F., 2012. Direct conversion of fibroblasts into stably expandable neural stem cells. Cell Stem Cell $10,473-479$.

Toft-Hansen, H., Nuttall, R.K., Edwards, D.R., Owens, T., 2004. Key metalloproteinases are expressed by specific cell types in experimental autoimmune encephalomyelitis. J. Immunol. 173, 5209-5218.

Torkildsen, O., Stansberg, C., Angelskar, S.M., Kooi, E.J., Geurts, J.J., van der Valk, P., Myhr, K.M., Steen, V.M., Bo, L., 2010. Upregulation of immunoglobulin-related genes in cortical sections from multiple sclerosis patients. Brain Pathol. 20, 720-729.

Tran, J., Palaparthy, R., Zhao, J., Brosofsky, K., Ray, S., Rana, J., Cadavid, D., 2012. Safety, tolerability and pharmacokinetics of the anti-LINGO-1 monoclonal antibody BIIB033 in healthy volunteers and subjects with multiple sclerosis. Neurology 78, (Meeting Abstract 1).

Trapp, B.D., Nave, K.A., 2008. Multiple sclerosis: an immune or neurodegenerative disorder? Annu. Rev. Neurosci. 31, 247-269.

Trapp, B.D., Stys, P.K., 2009. Virtual hypoxia and chronic necrosis of demyelinated axons in multiple sclerosis. Lancet Neurol. 8, 280-291.

Trapp, B.D., Peterson, J., Ransohoff, R.M., Rudick, R., Mork, S., Bo, L., 1998. Axonal transection in the lesions of multiple sclerosis. N. Engl. J. Med. 338, 278-285.

Tuohy, O., Costelloe, L., Hill-Cawthorne, G., Bjornson, I., Harding, K., Robertson, N., May, K., Button, T., Azzopardi, L., Kousin-Ezewu, O., Fahey, M.T., Jones, J., 
Compston, D.A., Coles, A., 2015. Alemtuzumab treatment of multiple sclerosis: long-term safety and efficacy. J. Neurol. Neurosurg. Psychiatry 86, 208-215.

Van der Valk, P., Amor, S., 2009. Preactive lesions in multiple sclerosis. Curr. Opin. Neurol. 22, 207-213.

Van der Walt, A., Butzkueven, H., Kolbe, S., Marriott, M., Alexandrou, E., Gresle, M. Egan, G., Kilpatrick, T., 2010. Neuroprotection in multiple sclerosis: a therapeutic challenge for the next decade. Pharmacol. Therap. 126, 82-93.

van Noort, J.M., van den Elsen, P.J., van Horssen, J., Geurts, J.J., van der Valk, P., Amor, S., 2011. Preactive multiple sclerosis lesions offer novel clues for neuroprotective therapeutic strategies. CNS Neurol. Disord. Drug Targets 10, 68-81.

van Oosten, B.W., Killestein, J., Barkhof, F., Polman, C.H., Wattjes, M.P., 2013. PML in a patient treated with dimethyl fumarate from a compounding pharmacy. N. Engl. J. Med. 368, 1658-1659.

Vennegoor, A., Rispens, T., Strijbis, E.M., Seewann, A., Uitdehaag, B.M., Balk, L.J., Barkhof, F., Polman, C.H., Wolbink, G., Killestein, J., 2013. Clinical relevance of serum natalizumab concentration and anti-natalizumab antibodies in multiple sclerosis. Mult. Scler. 19, 593-600.

Vermersch, P., Czlonkowska, A., Grimaldi, L.M., Confavreux, C., Comi, G., Kappos, L., Olsson, T.P., Benamor, M., Bauer, D., Truffinet, P., Church, M., Miller, A.E., Wolinsky, J.S., Freedman, M.S., O'Connor, P., Group, T.T., 2014. Teriflunomide versus subcutaneous interferon beta-1a in patients with relapsing multiple sclerosis: a randomised, controlled phase 3 trial. Mult. Scler. 20, 705-716.

Viglietta, V., Baecher-Allan, C., Weiner, H.L., Hafler, D.A., 2004. Loss of functional suppression by $\mathrm{CD} 4+\mathrm{CD} 25+$ regulatory $\mathrm{T}$ cells in patients with multiple sclerosis. J Exp Med 199, 971-979.

Vollmer, T., Stewart, T., Baxter, N., 2010. Mitoxantrone and cytotoxic drugs' mechanisms of action. Neurology 74 (Suppl. 1), S41-S46.

Vrenken, H., Pouwels, P.J., Geurts, J.J., Knol, D.L., Polman, C.H., Barkhof, F., Castelijns, J.A., 2006. Altered diffusion tensor in multiple sclerosis normal-appearing brain tissue: cortical diffusion changes seem related to clinical deterioration. J. Magn. Reson. Imaging 23, 628-636.

Waubant, E., Maghzi, A.-H., Revirajan, N., Spain, R., Julian, L., Mowry, E.M., Marcus, J. Liu, S., Jin, C., Green, A., McCulloch Charles, E., Pelletier, D., 2014. A randomized controlled phase II trial of riluzole in early multiple sclerosis. Ann. Clin. Transl. Neurol. 1, 340-347.
Waxman, S.G., 2006. Axonal conduction and injury in multiple sclerosis: the role of sodium channels. Nat. Rev. Neurosci. 7, 932-941.

Waxman, S.G., Ritchie, J.M., 1993. Molecular dissection of the myelinated axon. Ann. Neurol. 33, 121-136.

Wegner, C., Esiri, M.M., Chance, S.A., Palace, J., Matthews, P.M., 2006. Neocortical neuronal, synaptic, and glial loss in multiple sclerosis. Neurology 67, 960-967.

Wekerle, H., Sun, D., Oropeza-Wekerle, R.L., Meyermann, R., 1987. Immune reactivity in the nervous system: modulation of T-lymphocyte activation by glial cells. J. Exp. Biol. 132, 43-57.

Willis, S.N., Stadelmann, C., Rodig, S.J., Caron, T., Gattenloehner, S., Mallozzi, S.S., Roughan, J.E., Almendinger, S.E., Blewett, M.M., Bruck, W., Hafler, D.A., O'Connor, K.C., 2009. Epstein-Barr virus infection is not a characteristic feature of multiple sclerosis brain. Brain 132, 3318-3328.

Willison, H.J., Linington, C., 2012. Antibodies to MOG in NMO: a seasoned veteran finds a new role. Neurology 79, 1198-1199.

Wokke, J., 1996. Riluzole. Lancet 348, 795-799.

Wolinsky, J.S., Narayana, P.A., O'Connor, P., Coyle, P.K., Ford, C., Johnson, K., Miller, A. Pardo, L., Kadosh, S., Ladkani, D., Group, P.R.T.S., 2007. Glatiramer acetate in primary progressive multiple sclerosis: results of a multinational, multicenter, double-blind, placebo-controlled trial. Ann. Neurol. 61, 14-24.

Wu, C., Ivars, F., Anderson, P., Hallmann, R., Vestweber, D., Nilsson, P., Robenek, H., Tryggvason, K., Song, J., Korpos, E., Loser, K., Beissert, S., Georges-Labouesse, E., Sorokin, L.M., 2009. Endothelial basement membrane laminin alpha5 selectively inhibits T lymphocyte extravasation into the brain. Nat. Med. 15, 519-527.

Wucherpfennig, K.W., Strominger, J.L., 1995. Molecular mimicry in T cell-mediated autoimmunity: viral peptides activate human $\mathrm{T}$ cell clones specific for myelin basic protein. Cell 80, 695-705.

Yamout, B., Hourani, R., Salti, H., Barada, W., El-Hajj, T., Al-Kutoubi, A., Herlopian, A., Baz, E.K., Mahfouz, R., Khalil-Hamdan, R., Kreidieh, N.M., El-Sabban, M., Bazarbachi, A., 2010. Bone marrow mesenchymal stem cell transplantation in patients with multiple sclerosis: a pilot study. J. Neuroimmunol. 227, 185-189.

Ziabreva, I., Campbell, G., Rist, J., Zambonin, J., Rorbach, J., Wydro, M.M., Lassmann, H., Franklin, R.J., Mahad, D., 2010. Injury and differentiation following inhibition of mitochondrial respiratory chain complex IV in rat oligodendrocytes. Glia 58 1827-1837. 